\title{
The role of anthropogenic aerosols in future precipitation extremes over the Asian Monsoon Region
}

\author{
Alcide D. Zhao ${ }^{1}$ (D) David S. Stevenson ${ }^{1} \cdot$ Massimo A. Bollasina ${ }^{1}$
}

Received: 7 March 2018 / Accepted: 19 October 2018 / Published online: 25 October 2018

(c) The Author(s) 2018

\begin{abstract}
The role of anthropogenic aerosols in future projections (up to 2100) of summertime precipitation and precipitation extremes over the Asian monsoon region is investigated, by comparing two sets of the Community Earth System Model (CESM1) large ensemble simulations under the Representative Concentration Pathway 8.5 scenario (RCP8.5) and the corresponding scenario with aerosol fixed at 2005 levels (RCP8.5_FixA). The model is verified to be performing well in capturing presentday (1986-2005) climate and precipitation extremes. Our results suggest that the Asian monsoon region would become progressively warmer and wetter in the future under RCP8.5, while precipitation extremes will be significantly aggravated due to anthropogenic aerosol mitigation, particularly over East Asia. Specifically, aerosol reductions are found to shift the distribution of precipitation mean and extremes to larger values. For example, aerosol reductions would result in an increased likelihood of extreme precipitation (e.g. the maximum consecutive 5-day precipitation amount) and related disasters. Sensitivities of changes in precipitation mean and extremes to local warming from aerosol reductions are much larger than that from greenhouse gas increases. This is particularly important over East Asia in accordance with larger magnitudes of aerosol reductions compared to South Asia. Finally, by investigating the response of the climate system to aerosol changes, our findings demonstrate that aerosol induced precipitation changes would be dominated by aerosol-radiation-cloud forcing over northern East Asia and aerosol forcing induced large-scale circulation anomalies over southern East and South Asia.
\end{abstract}

Keywords Precipitation extremes · Anthropogenic aerosols $\cdot$ RCP8.5 $\cdot$ Asian Summer Monsoon

\section{Introduction}

The Fifth Assessment Report (AR5) of the Intergovernmental Panel on Climate Change (IPCC) concluded that "warming of the climate system is unequivocal and almost certainly caused by anthropogenic activities" (Flato et al. 2013; Stocker 2014). While climate change leads to variations in a wide range of aspects, it is most directly perceived by the public through increased frequency, duration and intensity of weather and climate extremes (Hansen et al. 1998; Peterson et al. 2013; Sillmann et al. 2013c). Climate extremes, defined

Electronic supplementary material The online version of this article (https://doi.org/10.1007/s00382-018-4514-7) contains supplementary material, which is available to authorized users.

Alcide D. Zhao

zhao.alcide@gmail.com

1 School of GeoSciences, University of Edinburgh, Edinburgh, UK as climate or weather events exceeding certain thresholds near the upper (or lower) end of the range of observations, can occur from the combined effects of natural variability and external anthropogenic forcings (Easterling et al. 2016). These extreme events pose tremendous risks to both human society and natural systems (Easterling et al. 2000; Knapp et al. 2008; Mascioli et al. 2016; Wang et al. 2016). For example, the 2003 European summer heat wave was estimated to cause well over 30,000 deaths (Brücker 2005). The 2011 floods in central and southern China affected over 36 million people with at least 355 deaths, and resulted in a direct economic loss of nearly US $\$ 6.5$ billion (Van Rij 2016). As such, reducing the uncertainty in future projections of climate extremes is of utmost importance (Zhou et al. 2014). In particular, precipitation extremes have been given specific attention given the importance of the hydrological cycle for water resources, health, agriculture, and ecosystems worldwide (Giorgi et al. 2011; Sillmann et al. 2013a, b, c; Polson et al. 2014; Freychet et al. 2015, 2016). 
The extensive Asian Summer Monsoon (ASM)—spanning South Asia (SA), Southeast Asia, and East Asia (EA) is essentially driven by the large-scale thermal contrast arising from the different heat capacities of land and ocean in response to the seasonal changes in solar radiation reaching the Earth's surface (Li et al. 2016b). The ASM plays a significant role in large-scale climate variability over much of the globe, and monsoon precipitation is crucial for the socioeconomic well-being and agriculture of billions of people. Asia, the world's most populated and fastest developing region, has witnessed dramatic economic, urban and industrial growth and has been the world's largest source of aerosols and their precursors over the last few decades (Li et al. 2016b). For instance, it was estimated that soot emissions grew by a factor of three in India and a factor of five in China during 1950-2002, while sulphur emissions increased sevenfold in India and tenfold in China (Ramanathan et al. 2007). From 2000 to 2014, as estimated by the Community Emissions Database System (CEDS), black carbon (BC) and organic carbon (OC) emissions follow similar increasing trends to those in the late twentieth century in most Asian countries (Crippa et al. 2016). In contrast, recent sulphur dioxide $\left(\mathrm{SO}_{2}\right)$ emissions are reported to show a downward trend over China but to still increase over India (Lu et al. 2011; Li et al. 2017a). The representative concentration pathway scenarios (RCPs) (Riahi et al. 2007; Lamarque et al. 2011; Van Vuuren et al. 2011) project, to varying extents, a decline of anthropogenic aerosol and aerosol precursor emissions worldwide over the coming decades, due to positive mitigation policies aimed at alleviating air pollution (Westervelt et al. 2015). In particular, significant aerosol reductions are expected over much of Asia due to stringent legislation. Since aerosols have long been found to significantly modulate climate locally and globally, it is important to understand and quantify whether precipitation extremes may change in response to future changes in aerosol emissions.

The availability of long-term global scale observations and improvements in climate modelling have allowed advances in our understanding of past changes of precipitation and precipitation extremes (Sen Roy and Balling 2004; Zhai et al. 2005; Orlowsky and Seneviratne 2012; Singh et al. 2014; Zhou et al. 2014; Freychet et al. 2015, 2016; Dong et al. 2016; Wang et al. 2016, 2017). For instance, the enhancement of the hydrological cycle is suggested to lead wet (dry) regions to become wetter (drier) (Held and Soden 2006; Tebaldi et al. 2006; Singh et al. 2013). This wet-getwetter paradigm, especially valid in the zonal-mean sense, is projected to continue in the future in response to continued warming, especially over the Northern Hemisphere (Min et al. 2011; Sillmann et al. 2013a, b, c). Changes in precipitation and precipitation extremes have so far been attributed variously to both internal natural variability (Chung and Ramanathan 2006; Qian and Zhou 2014) and external forcings, including greenhouse gases (GHGs) and aerosols (Polson et al. 2014; Mascioli et al. 2016; Lau and Kim 2017; Ma et al. 2017). Changes in mean precipitation have been largely linked to the variation in the water vapour holding capacity of the atmosphere with global-mean temperature in response to changes in a forcing agent-as specified by the Clausius-Clapeyron (CC) scaling, at a rate of $7 \% \mathrm{~K}^{-1}$. However, this thermodynamical control on precipitation changes is partially offset by a slowdown of the atmospheric circulation in order to satisfy global energetic constraints, resulting in a much smaller change per unit warming $\left(1-3 \% \mathrm{~K}^{-1}\right)$ (Allen and Ingram 2002; Wentz et al. 2007; Pendergrass and Hartmann 2014; O'Gorman 2015; Burke and Stott 2017). Precipitation extremes are mainly constrained by lowertropospheric moisture availability and supply within individual weather systems that are more related to local-scale, short time period effects rather than the global-scale energy budget. Although precipitation extremes follow the CC relation more closely than mean precipitation (Lin et al. 2016), deviations have been observed, including changes at a superCC scaling, due to the influence of multiple thermodynamic and dynamic factors (Caesar and Lowe 2012; Westra et al. 2013). Besides, studies also claim that regional precipitation extremes scale more strongly with dew point temperature rather than absolute temperature, e.g., over India (Ali and Mishra 2017, 2018; Mukherjee et al. 2018).

By directly absorbing or scattering solar (and, to a much lesser extent, terrestrial) radiation, aerosols can disturb the Earth's radiation budget (the direct radiative effect) (Haywood and Ramaswamy 1998) and hence impact surface temperature (Mateos et al. 2013). In addition, by acting as cloud condensation nuclei (CCN) or ice nuclei (IN), aerosols modify cloud microphysical properties (referred to as aerosol-cloud interactions or aerosol indirect effects) including cloud lifetime and cloud albedo, and thereby influence precipitation formation through complex mechanisms (Boucher et al. 2013; Polson et al. 2014; Fan et al. 2016; Lohmann et al. 2016). Furthermore, absorbing aerosols can also "burn off" clouds (the semi-direct effect) and hence perturb the thermal structure of the atmosphere through heating the layers where they reside (Koch and Del Genio 2010). However, a number of factors, including aerosol's heterogeneous spatial distribution, short life time, varied composition, as well as uncertainties in aerosol-cloud-climate interactions, make identifying the impact of aerosols on precipitation processes particularly difficult (Malavelle et al. 2017).

A number of studies have shown that aerosols have substantial effects on precipitation and precipitation extremes (Ramanathan et al. 2005; Polson et al. 2014; Sanap et al. 2015) via complex, and in some cases, competing mechanisms. For instance, increases in aerosols during the twentieth century have been found to contribute remarkably to the 
decrease in the Northern Hemisphere precipitation (Polson et al. 2013); the meridional shift of the Inter-Tropical Convergence Zone (Hwang et al. 2013), the weakening trend of the South Asian summer monsoon (Bollasina et al. 2011), the so-called summer "Southern-Flood-Northern-Drought" (SFND) pattern over the East China (Gong and Ho 2002; Song et al. 2014; Deng and Xu 2016; Li et al. 2016), as well as the shift of rainfall towards heavy mode over the East China (Ma et al. 2017). By investigating changes in temperature and precipitation extremes under different future emission scenarios, it was found that future GHG-induced changes will be strongly exacerbated under global aerosol reduction (Sillmann et al. 2013c). In addition, aerosols are suggested to have competing influences which offset GHG effects at regional scales such as over North America (Mascioli et al. 2016). More recently, it was suggested that future aerosol reductions will lead to a significant increase in precipitation extremes over Asia (Wang et al. 2016), a topic we investigate further here.

Despite recent advances in our understanding of aerosol-monsoon interactions, the extent to which anthropogenic aerosols affect the monsoon and the underlying mechanisms are still largely uncertain. In particular, identifying the aerosol imprint on precipitation extremes is even more challenging. In this study, we seek to quantify the effect of anthropogenic aerosol reductions on future projections of summertime precipitation extremes over Asia using simulations from the Community Earth System Model Large Ensemble (CESM-LE) (Kay et al. 2015). The availability of a large ensemble of experiments allows us to investigate the effects of anthropogenic aerosols while accounting for the uncertainty associated with internal variability of the climate system.

The remainder of the paper is organised as follows: data and methods used are described in Sect. 2. The CESM-LE performance in simulating observed historical (1986-2005) precipitation and precipitation extremes is evaluated in Sect. 3. Next, we examine the twenty-first century (2006-2100) spatio-temporal evolution of mean and extreme precipitation, and identify the impact of anthropogenic aerosol changes, including the possible underlying mechanisms in Sect. 4. Finally, discussion and conclusions follow in Sect. 5.

\section{Data and methodology}

The main dataset used in this study consists of a unique set of twentieth and twenty-first century transient experiments conducted with the CESM1 fully-coupled oceanatmosphere-land-sea-ice model at a horizontal resolution of $0.9^{\circ} \times 1.25^{\circ}$ in the atmosphere $\left(1^{\circ} \times 1^{\circ}\right.$ in the ocean) (Hurrell et al. 2013). Each experiment consists of a large number of ensemble members, specifically designed to quantify the contribution of internal variability to climate change projections (Deser et al. 2012). The Community Atmosphere Model 5 (Conley et al. 2012), the atmospheric component of CESM1, includes a three-mode (Aitken, accumulation, and coarse) aerosol scheme (MAM3) (Conley et al. 2012; Liu et al. 2012). MAM3 simulates several aerosol species (sulphate, organic carbon (OC, primary plus secondary organic carbon), black carbon (BC), sea-salt, and dust) and calculates aerosol number concentrations and masses under the assumption that aerosols are 'internally mixed' (i.e. well-mixed mixtures of their component species). CESM1 has been shown to capture the observed geographical and temporal variations of aerosol properties (Liu et al. 2012; Hurrell et al. 2013), and has been used in several studies focusing on climate extremes (Lin et al. 2015, 2016; Xu et al. 2015; Hagos et al. 2016; Wang et al. 2016). Also, the model simulated twenty-first century climate is described in Hurrell et al. (2013).

We utilize two sets of CESM-LE simulations in this study. Firstly, a 30-member ensemble of transient simulations driven by historical forcing during 1920-2005 and following the RCP8.5 pathway from 2006 to 2100 (Riahi et al. 2007; Van Vuuren et al. 2011). The RCP8.5 scenario assumes a global annual mean radiative forcing of $8.5 \mathrm{~W} \mathrm{~m}^{-2}$ by 2100 relative to pre-industrial times. Each of the 30 members have the same forcing trajectory but start from randomly perturbed initial atmospheric conditions (Kay et al. 2015). Secondly, a 15-member ensemble of simulations with the same time-varying forcing as RCP8.5 but with fixed aerosol/precursor emissions at 2005 levels (hereinafter RCP8.5_FixA for short) (Lin et al. 2015; Xu et al. 2015). Note, however, that aerosol concentrations in RCP8.5_FixA do evolve slightly regional: differences up to $5-10 \%$ by 2010 (Lin et al. 2015) due to transport and removal processes associated with the different climate. Under RCP8.5_FixA, the net warming is primarily due to changes in GHGs with minor contributions from other factors such as land use changes (Xie et al. 2013; Shindell et al. 2015; Paul et al. 2016). Therefore, we hereinafter refer to changes under RCP8.5_FixA as GHG effects. Assuming linearity in the combined responses, the difference between RCP8.5 and RCP8.5_FixA represents the climate effect due to time-evolving anthropogenic aerosol emissions. Note although non-linear interactions between GHGs and aerosol exist, we still attribute them to aerosol effects as such non-linearity emerges only when additional anthropogenic aerosols are present.

In addition to the output from the CESM1 experiments, we made use of observational datasets to evaluate the present-day model climatology. Daily precipitation from the Asian Precipitation Highly-Resolved Observational Data Integration Towards Evaluation (APHRODITE; Yatagai 
et al. 2012) dataset at $0.5^{\circ} \times 0.5^{\circ}$ resolution (interpolated to the model grid) was used to compute observed mean and extreme precipitation over the Asian Monsoon Region. APHRODITE is the only long-term (1951-onward) continental-scale product that makes use of a dense network of daily rain-gauge data for Asia (Yatagai et al. 2012). Additionally, the model simulated mean surface air temperature and $850 \mathrm{hPa}$ winds were compared to those from the NCEP/NCAR reanalysis (Kalnay et al. 1996) at $2.5^{\circ} \times 2.5^{\circ}$ resolution.

Given the complex interplay and the existence of major differences in the underlying mechanisms between the two main sub-components of the Asian monsoon, the South Asian and East Asian monsoons (Yihui and Chan $2005)$, the analysis is performed separately for South $\left(5^{\circ}-30^{\circ} \mathrm{N}, 65^{\circ}-100^{\circ} \mathrm{E}\right)$ and East $\left(20^{\circ}-50^{\circ} \mathrm{N}, 100^{\circ}-145^{\circ} \mathrm{E}\right)$ Asia (Giorgi and Francisco 2000), as defined in Fig. 1. Extreme precipitation is characterised by four indices chosen from those defined by the Expert Team on Climate Change Detection and Indices (ETCCDI) (Alexander et al. 2006; Zhang et al. 2011), described in Table 1. This study focuses on the Northern Hemisphere summer (June-July-August, hereinafter JJA), when the monsoon is fully established over Asia (Wang 2006). All the precipitation indices are computed over JJA at each land gridcell for all the ensemble members of the two scenarios.
To isolate aerosol effects, we also compute the difference between the mean of the two ensemble members, while their statistical significance is evaluated by the non-parametric Mann Whitney U test (Chu et al. 2010). Future change of each precipitation index is calculated as an anomaly relative to the 1986-2005 mean baseline. Note that area-averaged quantities are computed by using landonly points. To produce time series of the index over SA and EA, each index is spatially averaged for each year of each ensemble member, and the ensemble median and spreads (5th-95th percentiles) for each year are provided. To produce spatial anomaly maps, the index in each gridcell is annually averaged throughout the time interval (e.g. 2031-2050) for each ensemble member. Then, the two ensemble sets of annually averaged maps (30 for RCP8.5 and 15 for RCP8.5_FixA) are used to calculate the statistical significance of the difference, and averaged across each set of ensemble members to produce the ensemble mean RCP8.5 and RCP8.5_FixA maps and their differences.
Fig. 1 Surface air temperature (SAT, shadings, ${ }^{\circ} \mathrm{C}$ ) and $850 \mathrm{hPa}$ winds (Winds850, arrows, $\left.\mathrm{m} \mathrm{s}^{-1}\right)$, 1986-2005 summertime (June-July-August, JJA) mean over the Asia monsoon region (AMR, $5^{\circ} \mathrm{S}-55^{\circ} \mathrm{N}$, $60^{\circ} \mathrm{E}-150^{\circ} \mathrm{E}$ ) derived from a CESM1 ensemble mean, and b NCEP reanalysis. Boxes denote South Asia (SA, $\left.5^{\circ} \mathrm{N}-30^{\circ} \mathrm{N}, 65^{\circ} \mathrm{E}-100^{\circ} \mathrm{E}\right)$ and East Asia (EA, $20^{\circ} \mathrm{N}-50^{\circ} \mathrm{N}$, $100^{\circ} \mathrm{E}-145^{\circ} \mathrm{E}$ ) respectively (a) CESM1 SAT+Winds850

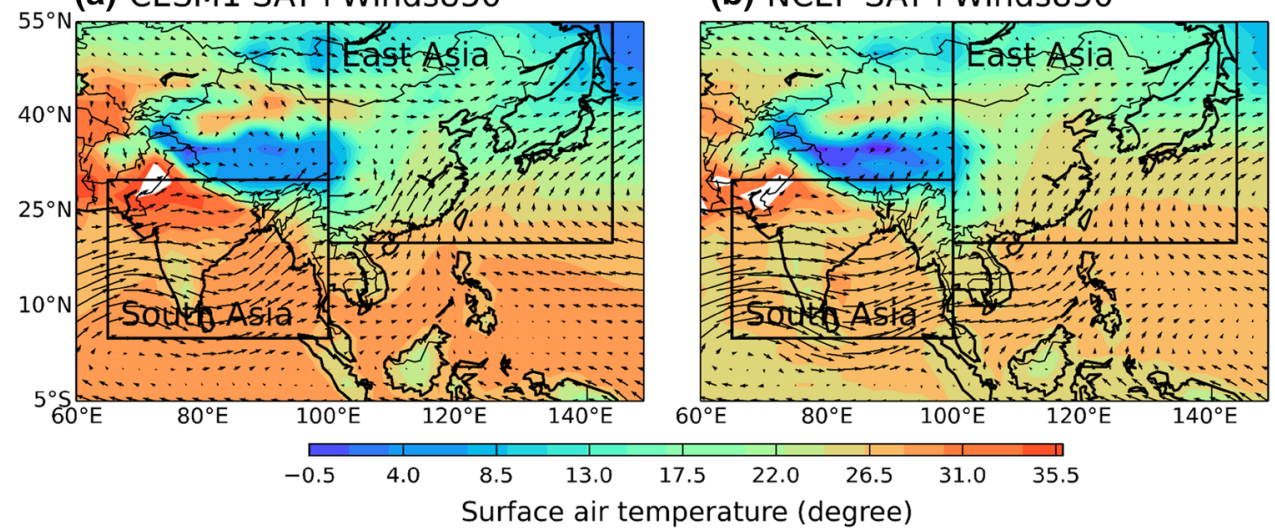

Table 1 Definition of the precipitation indices used in this paper, wet day is referred when daily precipitation $\geq 1 \mathrm{~mm}$, the 95 th percentile threshold is calculated from the $1961-1990$ daily precipitations

\begin{tabular}{llll}
\hline Acronym & Name & Brief definition & Units \\
\hline & Mean precipitation & Mean of daily precipitation & $\mathrm{mm} \mathrm{day}^{-1}$ \\
RX5DAY & Maximum consecutive 5-day precipitation & The maximum of consecutive 5-day precipitation & mm \\
R10 & Heavy precipitation frequency & Count of days with precipitation $\geq 10 \mathrm{~mm}$ & days \\
CWD & Maximum duration of wet spell & Maximum number of consecutive wet days & days \\
R95P & Amount of extreme precipitation & Total of precipitation $\geq 95$ th percentile & mm \\
\hline
\end{tabular}

All the indices are calculated over the Northern Hemisphere summer (June-July-August, JJA) 


\section{Model evaluation: present-day climate and precipitation extremes}

The performance of CESM1 in capturing climate extremes has been evaluated over the globe (Kharin et al. 2013; Sillmann et al. 2013a) and local regions such as China (Wang et al. 2016). To provide a further indication of the performance of the CESM-LE in reproducing precipitation extremes over the Asian monsoon region, we compare climatology fields and precipitation extremes derived from CESM-LE to observations/reanalysis during 1986-2005. Figure 1 shows a comparison between observed and simulated JJA surface air temperature and $850-\mathrm{hPa}$ winds. The model shows agreement with the reanalysis in capturing both the spatial pattern and the magnitudes of temperature as well as winds. The major monsoon trough over the South China Sea (SCS), the subtropical anti-cyclonic circulation with strong south-westerlies from the Indian Ocean that converges over the SCS with the easterlies from the tropical Pacific, and also the higher latitude westerlies are all notable features well represented by CESM1.

Figure 2 compares observed and simulated seasonal (JJA) mean and standard deviation of daily precipitation. Generally, both the climatological mean and variability are captured reasonably well by the model, although when the model is averaged over the whole region it tends to produce overestimates. Such overestimates are most significant over the Himalayas-Tibetan plateau, southern India and Northeast China (Fig. 2e, f). On the contrary, precipitation is underestimated over central India and a large proportion of South China. Quantitatively, a positive bias in mean precipitation of $0.95 \mathrm{~mm} \mathrm{day}^{-1}(19 \%)$ and $1.56 \mathrm{~mm} \mathrm{day}^{-1}$ (23\%) is found over SA and EA, respectively; while the bias for precipitation variability is respectively $1.21 \mathrm{~mm} \mathrm{day}^{-1}(14 \%)$ and $1.01 \mathrm{~mm} \mathrm{day}^{-1}(12 \%)$. In addition, a comparison of historical changes (1986-2005 minus 1951-1970) in precipitation extremes between the model and APHRODITE was carried out (Fig. S1). There exist similarities between the model and APHRODITE in capturing these historical changes, with significant differences though. It should be noted that detailed reproduction of observed changes in extreme indices is particularly challenging for a model, and some biases are inevitable and to be expected. Note that these findings are consistent with recent multi-model evaluations (Ashfaq et al. 2017), which deemed CESM1 to be among the best performing models in simulating a number of features of the South Asian monsoon.
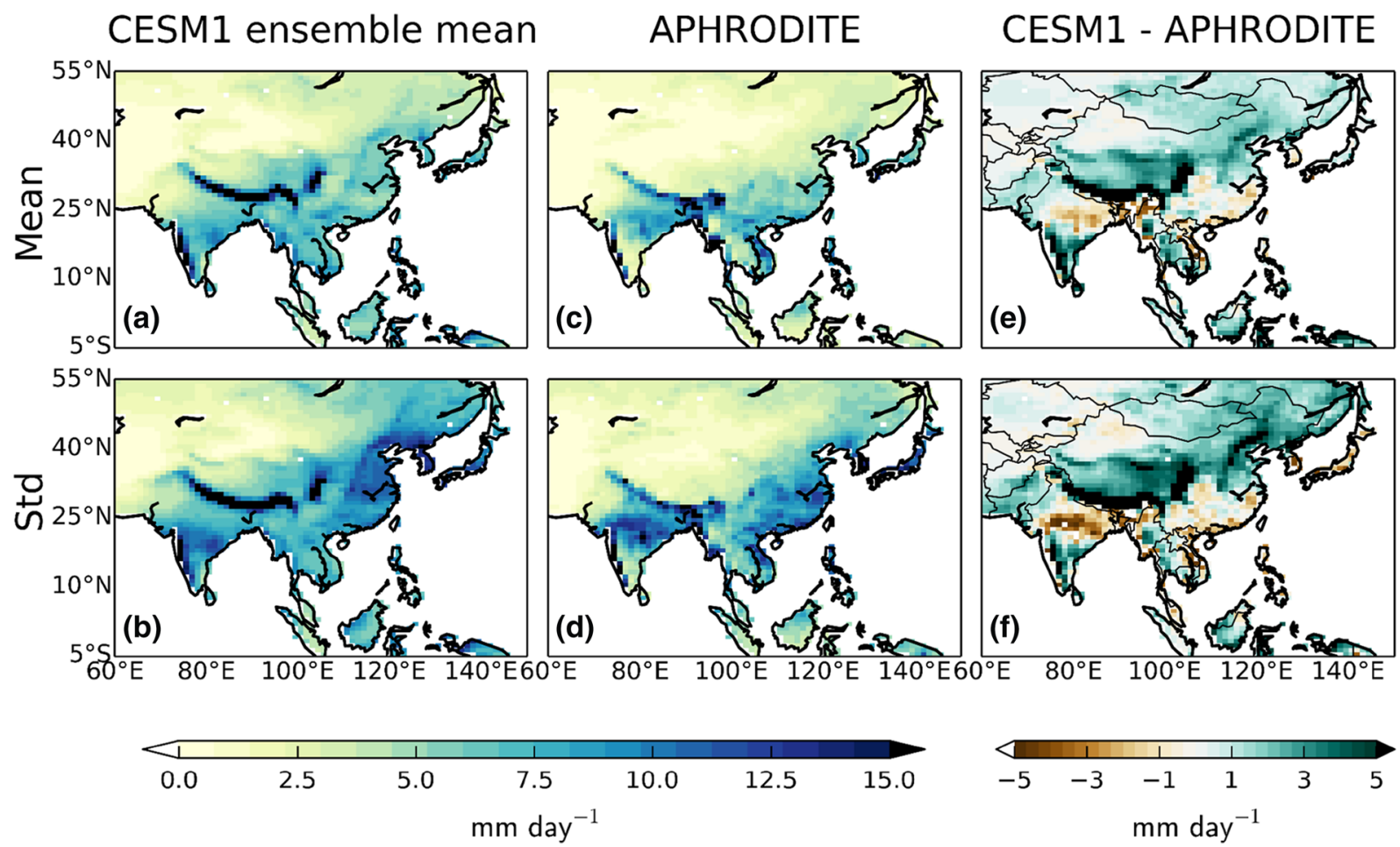

Fig. 2 Daily precipitation $\left(\mathrm{mm} \mathrm{day}^{-1}\right)$, 1986-2005 JJA a, c mean and $\mathbf{b}, \mathbf{d}$ variability of derived from $\mathbf{a}, \mathbf{b}$ APHRODITE, $\mathbf{c}, \mathbf{d}$ CESM1 ensemble mean, and e, f the difference between CESM1 ensemble mean and APHRODITE. The APHRODITE data were interpolated to the CESM1 grid $\left(0.9^{\circ} \times 1.25^{\circ}\right)$ 
Albeit incomplete, the above analysis shows that CESM1 captures the key climatological features of the Asian summer monsoon, which provides a solid foundation for using it to investigate precipitation changes and extremes. Figure 3 shows the precipitation extreme indices (RX5DAY, R10, CWD, and R95P) averaged throughout 1986-2005 for the ensemble mean of CESM1 as well as APHRODITE. In general, the model can reproduce these indices well although some biases are found regionally. The probability distribution functions (PDFs) for these extreme indices over SA and EA throughout 1986-2005, calculated from APHRODITE and the CESM1 ensemble members in Fig. 3, demonstrate that the model-simulated historical precipitation extremes generally agree with APHRODITE. However, the model tends to produce slight overestimates. Furthermore, with the exception of CWD over EA, all of the four precipitation extreme indices over EA and SA are greater than over the rest of the Asian Continent. This indicates that at present EA and SA feature relatively more extreme precipitation compared to their surroundings. This is also noted by CMIP5 studies (Sillmann et al. 2013a) and observations (Alexander et al. 2006). In summary, we conclude that CESM1 is a viable tool to study precipitation extremes over the AMR.

\section{Future projections to 2100}

This section describes the spatio-temporal evolution of the selected precipitation indices following the RCP8.5 scenario, as well as the contribution of anthropogenic aerosol changes represented by the difference between RCP8.5 and RCP8.5_FixA. We start by describing the future evolution of anthropogenic aerosol/precursor emissions and the resultant variations in aerosol burdens under the two scenarios in Sect. 4.1. Next, changes in precipitation and precipitation extremes due to aerosols are discussed in Sect. 4.2. Finally,
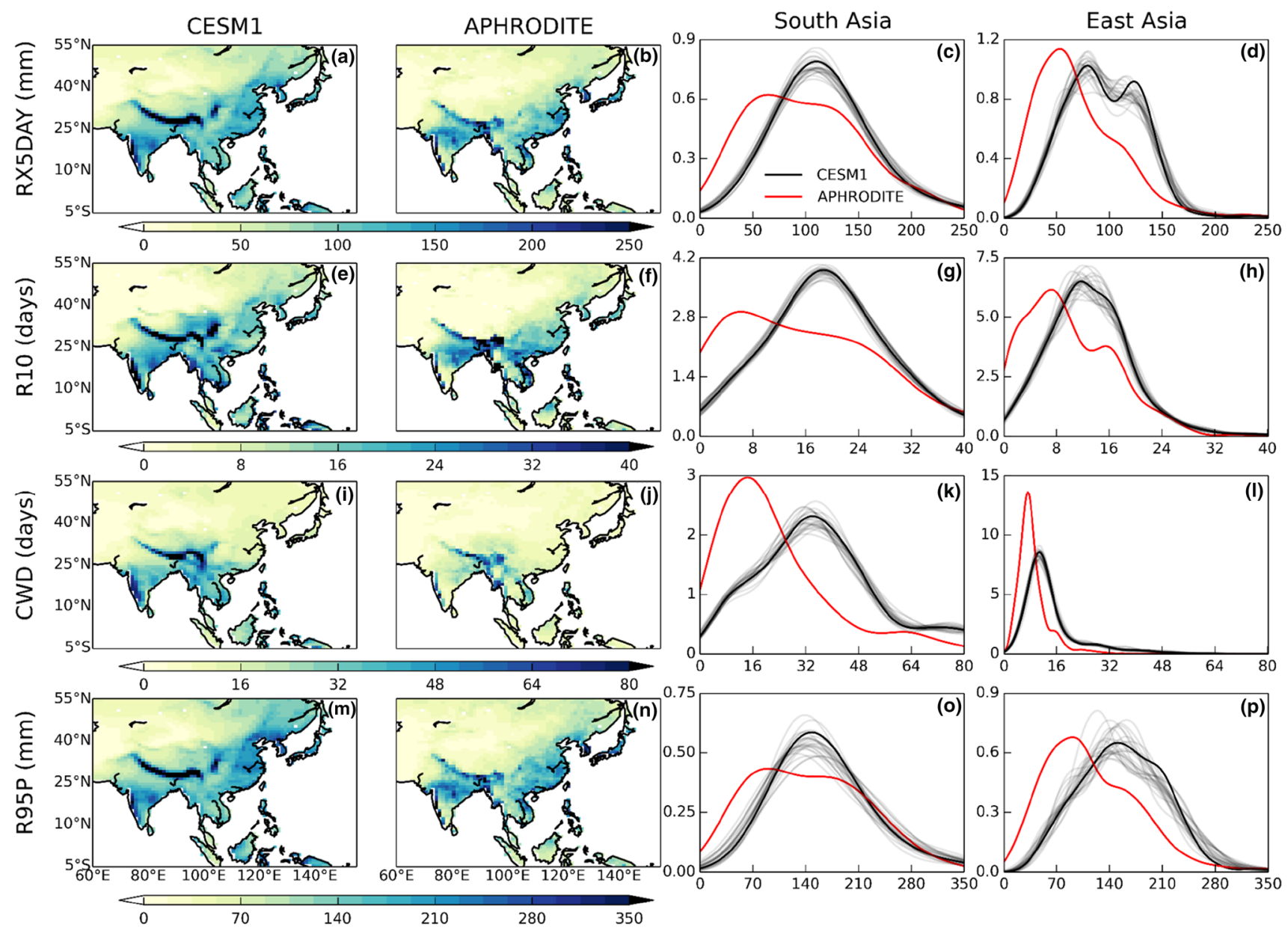

Fig. 3 Comparison of 1986-2005 JJA extreme precipitation indices [a-d RX5DAY (mm); e-h R10 (days); i-l CWD (days); and $\mathbf{m}-\mathbf{p}$ R95P (mm)], simulated by CESM1 ensemble mean (first column) and derived from APHRODITE observations (second column). For definitions of indices, see Table 1. Third column (SA) and fourth column
(EA) show probability density functions (PDFs, \%) based on the spatially resolved data for each CESM1 ensemble members (grey lines), the ensemble mean (black line), and APHRODITE (red line) (all at the model resolution of $0.9^{\circ} \times 1.25^{\circ}$ ) 
Sect. 4.3 investigates the physical mechanisms driving these changes, by examining aerosol induced changes in cloud properties, radiation budgets, as well as thermodynamic and dynamic fields. Future changes of precipitation indices are presented as differences with respect to the baseline (1986-2005).

\subsection{Changes in aerosol emissions and burdens}

The RCP scenarios assume increasingly more stringent anthropogenic aerosol mitigations with time, including a substantial reduction of sulphur dioxide $\left(\mathrm{SO}_{2}\right), \mathrm{BC}$ and $\mathrm{OC}$ emissions (Gillett and Von Salzen 2013). Figure 4 shows the time evolution (2006-2100) of summertime anthropogenic aerosol emissions for the RCP8.5 pathway together with the CESM1 simulated aerosol burdens over the AMR, EA and SA. Given the short aerosol residence time in the atmosphere, it is not surprising that temporal changes in aerosol burdens closely follow those of emissions. As such, we hereinafter discuss only aerosol burdens unless otherwise specified.
Changes in sulphate aerosol $\left(\mathrm{SO}_{4}\right)$ are the most pronounced in magnitude and differ between EA and SA. More specifically, $\mathrm{SO}_{4}$ over SA increases to peak around 2020-2040 and then declines steadily to below its 2005 level after the 2050s. By 2100 , the summertime $\mathrm{SO}_{4}$ burden over the AMR will have decreased by around $2.8 \mathrm{Tg}(-67 \%)$ with the largest changes $(1.4 \mathrm{Tg},-80 \%)$ arising from EA. The BC burden increases to peak around the 2010s in EA and the 2050s in SA, then decreases relative to 2005 by around $0.12 \mathrm{Tg}(-52 \%)$ over the AMR and $0.08 \mathrm{Tg}(-75 \%)$ over EA by the end of this century. The BC burden over SA, by comparison, increases by $0.01 \mathrm{Tg}(+22 \%)$ up to 2050 and then drops back to the 2005 level by the 2090s. Changes in OC tell almost the same story as BC throughout the century, except for a larger magnitude. Note the percentage changes are calculated relative to the simultaneous aerosol burdens simulated under RCP8.5_FixA.

The simulated differences, averaged over 2031-2050 and 2081-2100 (highlighted by the pink shadings in Fig. 4), of summertime $\mathrm{BC}, \mathrm{OC}$ and $\mathrm{SO}_{4}$ burden as well as the Aerosol Optical Depth at $550 \mathrm{~nm}$ (AOD) over the Asian monsoon region are shown in Fig. 5. These two time periods
Fig. 4 Time evolution (anomalies relative to 2005) of JJA aerosol/precursor emissions (dotted lines, left axis, blue for black carbon (BC), green for organic carbon (OC), and red for sulphur dioxide $\left(\mathrm{SO}_{2}\right)$, $\mathrm{Mg} \mathrm{s}^{-1}$ ), and aerosol burdens (solid lines, right axis, blue for $\mathrm{BC}$, green for $\mathrm{OC}$, and red for sulphate $\left(\mathrm{SO}_{4}\right)$ respectively, $\left.\mathrm{Tg}\right)$ accumulated over land gridcells of a AMR, $\mathbf{b}$ EA and $\mathbf{c}$ SA. The aerosol burdens shown are the difference between RCP8.5 and RCP8.5_FixA. The pink shadings from left to right highlight the time period 2031-2050 and 2081-2100, respectively

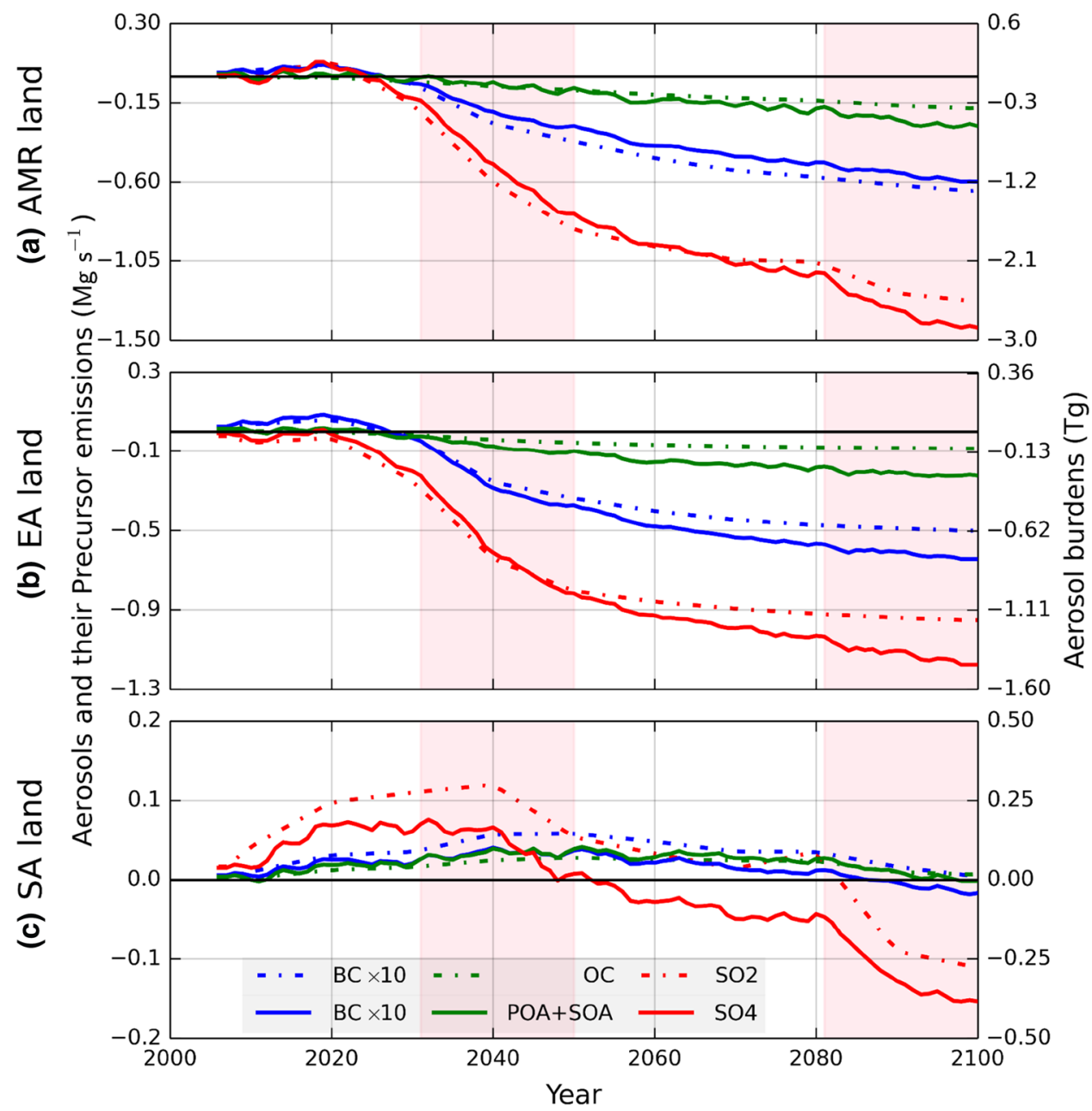



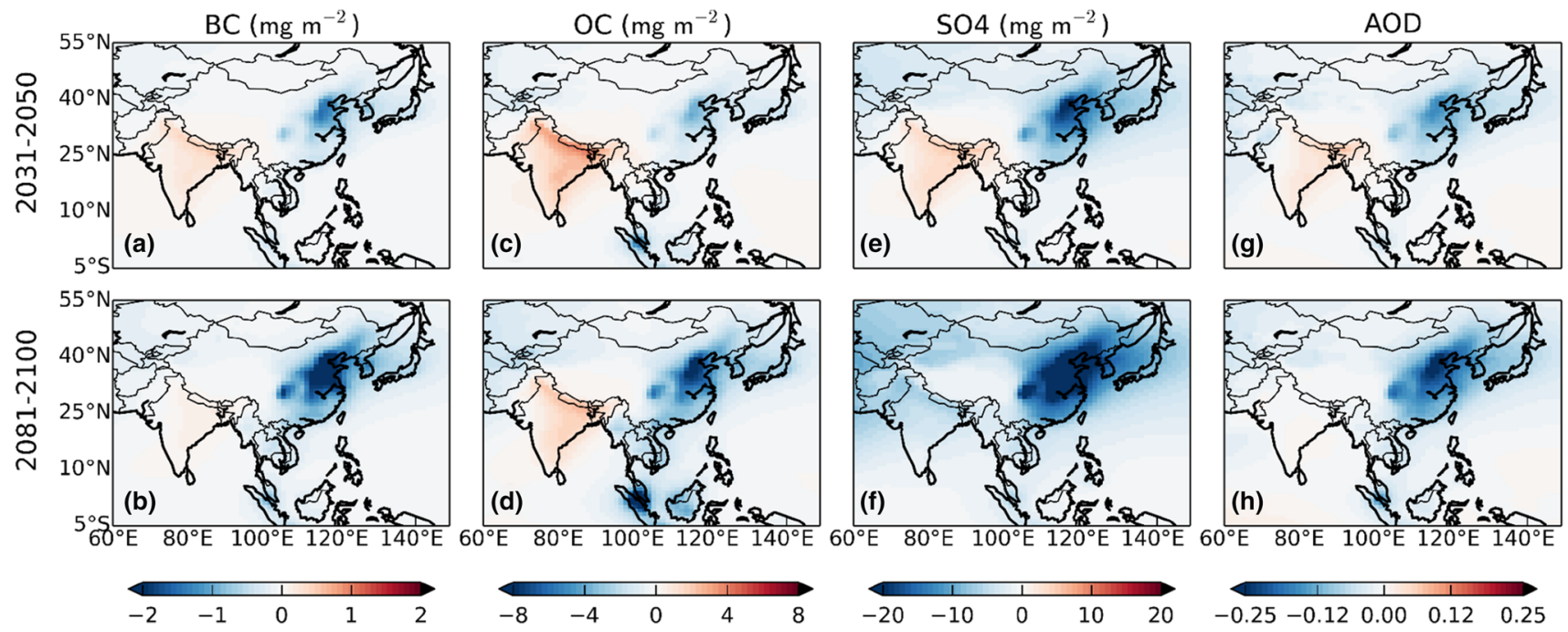

Fig. 5 Difference in aerosol burdens $\left(\mathrm{mg} \mathrm{m}^{-2}\right.$ ) between RCP8.5 and RCP8.5_FixA, for a, b BC, $\mathbf{c}, \mathbf{d}$ OC, and $\mathbf{e ,} \mathbf{f} \mathrm{SO}_{4}$, as well as $\mathbf{g}, \mathbf{h}$ Aerosol Optical Depth (AOD) at the wavelength of 550 nm averaged throughout 2031-2050 (top) and 2081-2100 (bottom)

are selected to show contrasting aerosol effects. Relative to RCP8.5_FixA, while $\mathrm{BC}, \mathrm{OC}$ and $\mathrm{SO}_{4}$ are projected to decline over EA during 2031-2050, SA shows increases in all three aerosol species, with peak relative increases of $26 \%$ (BC), 23\% (OC) and 32\% ( $\mathrm{SO}_{4}$ ) over the Indo-Gangetic plain. As a result, AOD differences between SA and EA up to 2031-2050 show changes with opposite signs, with an average increase of 0.04 for SA and an average decrease of 0.06 for EA. By 2081-2100, the aerosol burden over EA is predicted to dramatically decrease. For $\mathrm{SA}$, in comparison, we still see increases in $\mathrm{BC}$ and $\mathrm{OC}$, whereas $\mathrm{SO}_{4}$ decreases slightly. The AOD pattern (Fig. $5 \mathrm{~g}, \mathrm{~h}$ ), mostly attributable to sulphate aerosol, shows reductions over EA $(-0.074$ on average) and East China (well below - 0.20) in particular, but relatively minor decreases over SA ( -0.006 on average) by $2081-2100$.

\subsection{Changes in precipitation and precipitation extremes}

The temporal evolution of projected changes in summertime surface air temperature, mean precipitation as well as precipitation extreme indices under RCP8.5 and RCP8.5_FixA over EA and SA are provided in Figs. 6 and 7 respectively. The spatial pattern of mean precipitation anomalies relative to the 1986-2005 climatology are presented in Fig. 8, while Fig. 9 shows the spatial patterns of the aerosol-induced differences in the precipitation extreme indices averaged over 2031-2050 and 2081-2100. Also see Fig S2 for the relative percentage changes in precipitation extremes. Under RCP8.5, where both GHGs and aerosols (Figs. 4, 5) change significantly, temperature increases rapidly with time, with a net warming by 2100 of up to $5.8 \mathrm{~K}$ over EA (Fig. 6a) and
4.4 K over SA (Fig. 7a). Accompanying the warming there is also an evident increase in mean precipitation, RX5DAY, R10 and R95P over both regions, whereas CWD increases in EA but decreases in SA. In the following sections, we focus on the difference between RCP8.5 and RCP8.5_FixA to isolate the effects of aerosols on variations in mean and extreme precipitation indices.

\subsubsection{Changes in mean precipitation}

Over EA, the net warming (Fig. 6a) associated with aerosol reductions becomes progressively larger over time. In comparison, increasing aerosol loading over SA (Figs. 4c, 5) does not produce an appreciable temperature change before 2040 (Fig. 7a). This can be because the cooling induced by sulphate aerosol increases is quite limited and is offset by the warming due to increases in absorbing aerosols (BC mainly). From 2040 onward, however, the net warming due to aerosol reductions becomes evident over both SA and EA, although the latter features large model internal variability. Changes in mean precipitation (Figs. 6b, 7b) show generally consistent trends with warming, but features a wide ensemble spread, especially over SA (Fig. 7b). There are relatively larger model internal spreads in all precipitation indices compared to temperature, although statistics indicate that aerosol changes induce changes in mean and extreme precipitation indices that are significant. The relatively larger model internal spread in precipitation indices is related to the heterogeneous nature of the precipitation response while the seasonal mean temperature responses have a more uniform spatial structure. Notably, warming induced by aerosol reductions has a proportionally larger impact on mean precipitation than that induced by GHG increases. This can 
(a) SAT (K)

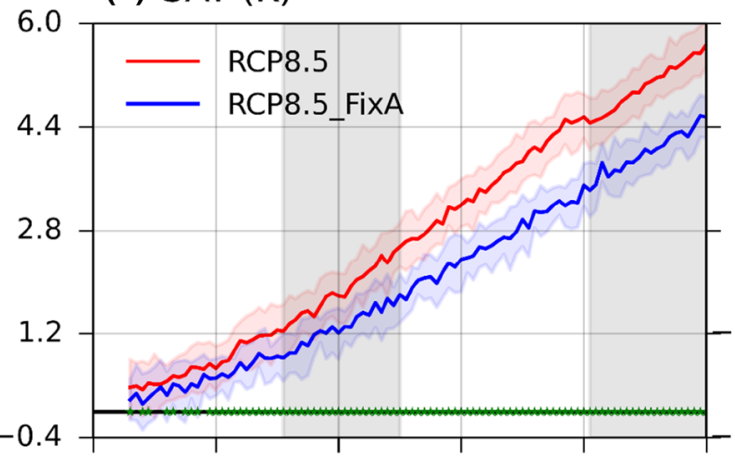

(c) RX5DAY (mm)

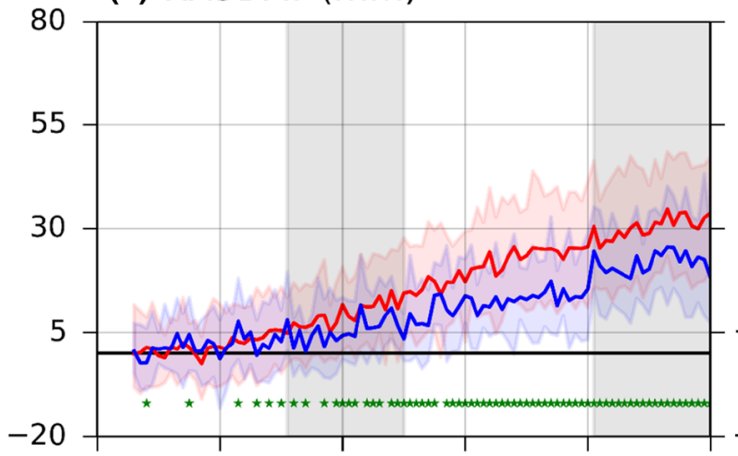

(e) CWD (days)

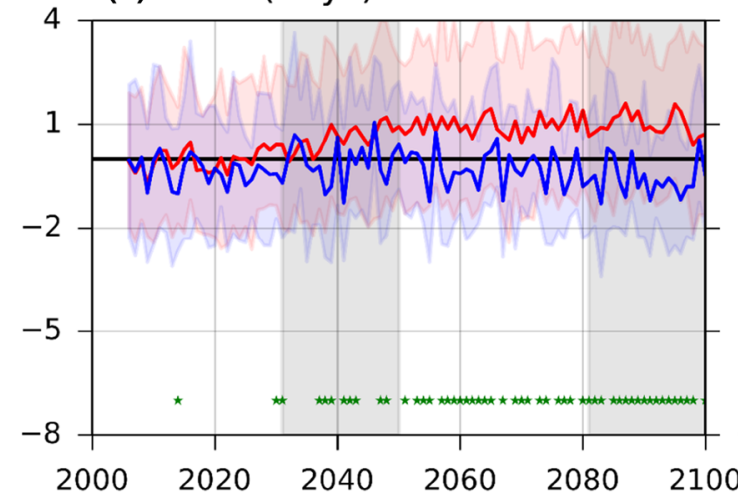

Fig. 6 Time evolution (anomalies relative to 1986-2005 mean), over EA, of spatially averaged JJA a surface air temperature (SAT, K), b precipitation mean $\left(\mathrm{mm} \mathrm{day}^{-1}\right)$, c RX5DAY (mm), d R10 (days), e CWD (days) and f R95P (mm), calculated for RCP8.5 (red, 30 ensemble members) and RCP8.5_FixA (blue, 15 ensemble members).

be clearly seen from 2060 onwards over both SA and EA. Over EA, the $1 \mathrm{~K}$ of warming from aerosol reductions by 2081-2100 is associated with a mean precipitation increase of approximately $0.5 \mathrm{~mm} \mathrm{day}{ }^{-1}$, whereas $4 \mathrm{~K}$ of warming from GHG increases results in the same amount of mean precipitation increase. As for SA, similarly, the $0.5 \mathrm{~K}$ of warming from aerosol reductions has the same effects on mean precipitation as $3 \mathrm{~K}$ of warming from GHGs.

The spatial pattern of mean precipitation changes (Fig. 8c) shows that, by 2031-2050, aerosol reductions over EA lead mean precipitation to increase over a large (b) PMEAN (mm day $\left.{ }^{-1}\right)$

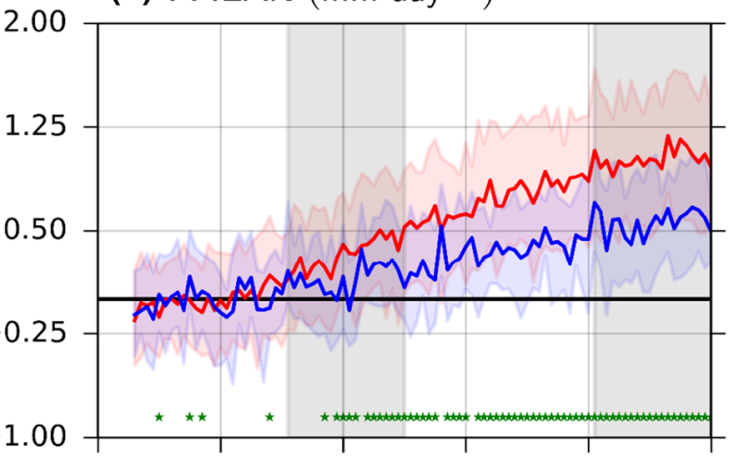

(d) R10 (days)

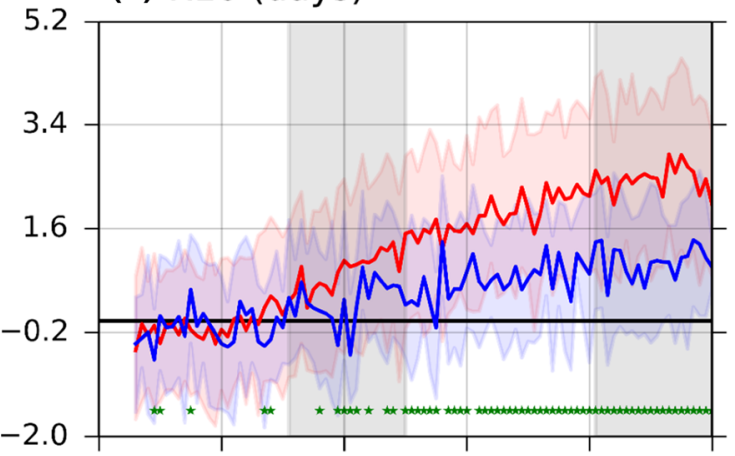

(f) $\mathrm{R} 95 \mathrm{P}(\mathrm{mm})$

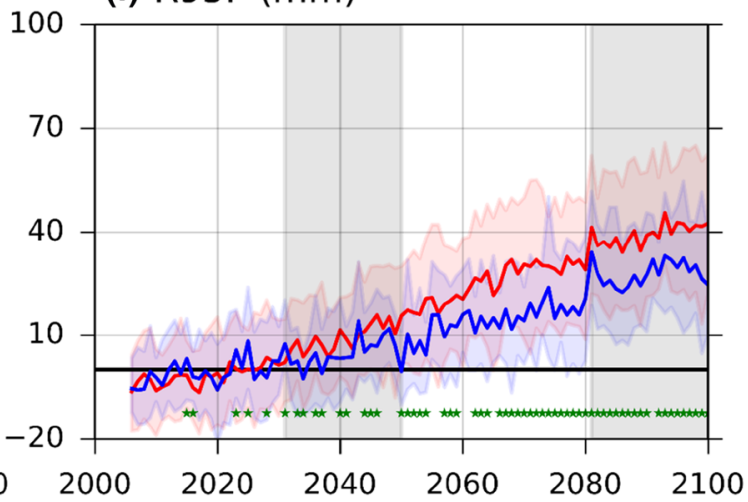

Solid curves indicate ensemble medians and shadings are 5th to 95th percentiles spreads. Green stars indicate $95 \%$ ( $p$ value $\leq 0.025$ ) statistical significance of the ensemble differences. Grey shadings highlight the time periods 2031-2050 and 2081-2100. Black horizontal line indicate no changes

proportion of Asia, whereas decreases are found over parts of the Himalayas-Tibetan Plateau. By 2081-2100, as shown in Fig. 8f, greater magnitudes of mean precipitation increases over a larger proportion of the AMR in accordance with additional aerosol reductions can be clearly seen. This is most pronounced over SE and E Asia. Moreover, over Eastern China under RCP8.5_FixA (Fig. 8b, e), there exists an evident dipole in the mean precipitation featuring a precipitation decrease to the north and strong wetting to the south along with GHG induced warming. The dipole resembles the recently observed Southern-Flood-Northern-Drought 
(a) SAT (K)

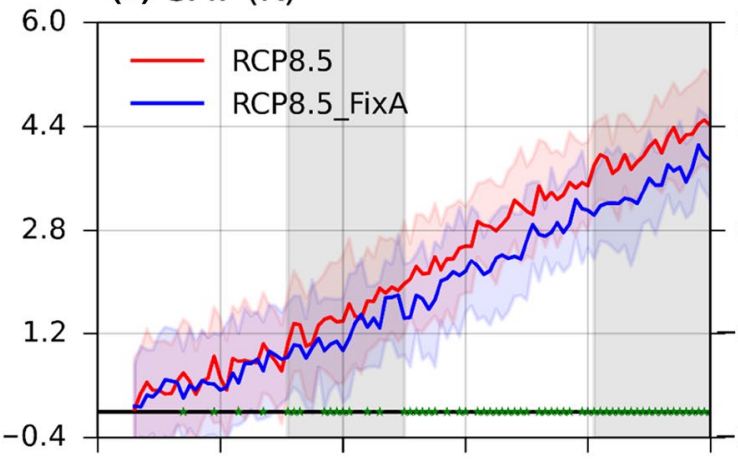

(c) RX5DAY (mm)

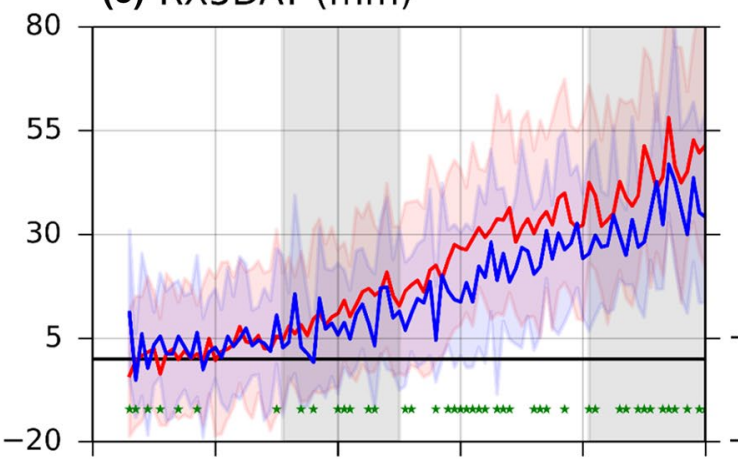

(e) CWD (days)

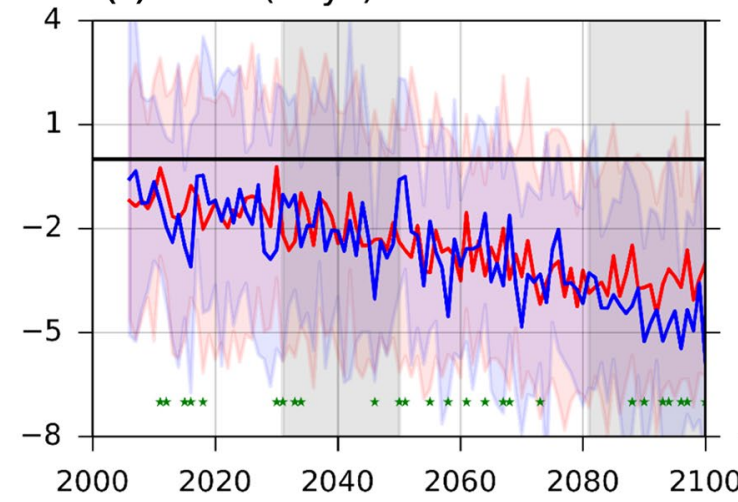

(b) PMEAN (mm day $\left.{ }^{-1}\right)$

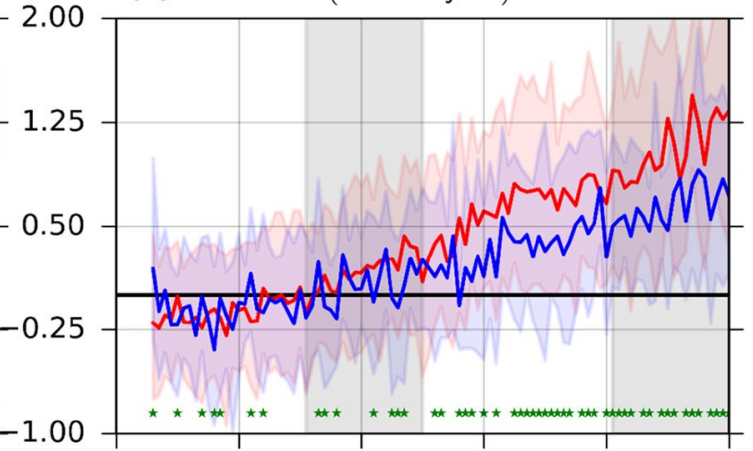

(d) R10 (days)

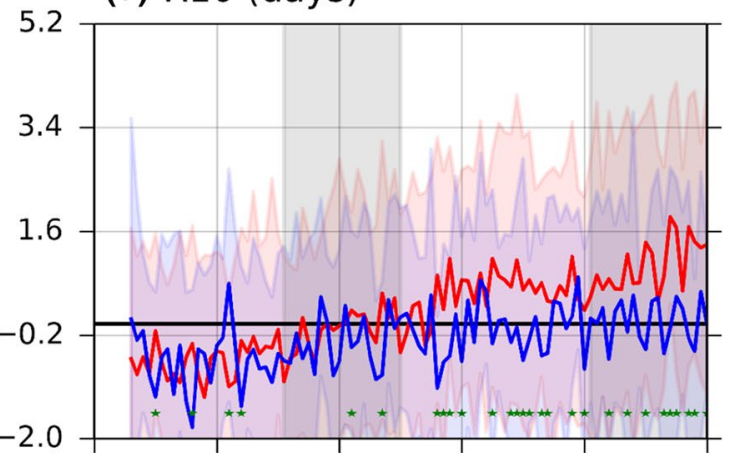

(f) $\mathrm{R} 95 \mathrm{P}(\mathrm{mm})$

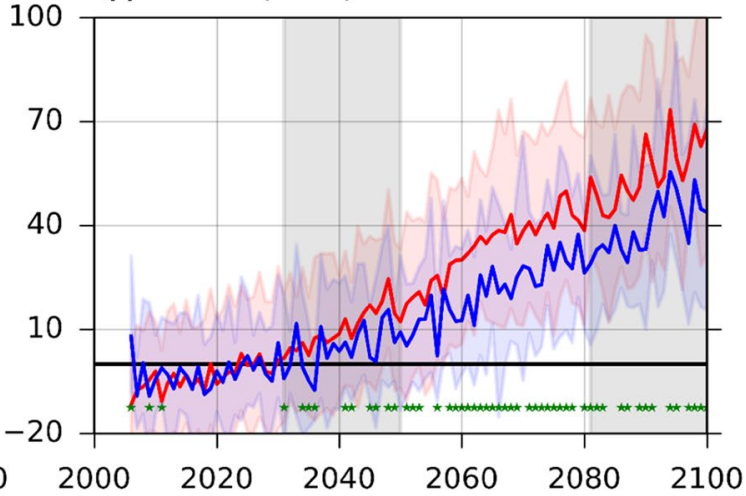

Fig. 7 Same as Fig. 6, but for SA

(SFND) pattern (Yu et al. 2010) which was found to be largely related to aerosol emissions (Jiang et al. 2013; Bartlett et al. 2016; Li et al. 2016a). However, this SFND pattern is substantially reduced under RCP8.5 (Fig. 8a, d), especially by 2081-2100 (Fig. 8d), due to aerosol induced increases in mean precipitation (Fig. 8c, f). Therefore, our results suggest that the SFND pattern might be alleviated with stringent aerosol emissions controls adopted in the future.

\subsubsection{Changes in precipitation extremes}

Figures 6, 7 and 9 show that, along with warming and mean precipitation increases because of aerosol changes, the associated changes in precipitation extremes become progressively more pronounced (with the exception of CWD over SA). Aerosol reductions lead RX5DAY to increase over a larger portion of the AMR from 2031 to 2050 (Fig. 9a) to 2081-2100 (Fig. 9b). Given that RX5DAY represents the maximum magnitude of heavy precipitation over a 5 day period, changes in RX5DAY can be used as a proxy for flooding and related hazards (Frich et al. 2002; Sillmann et al. 2013b). Therefore, changes in RX5DAY between RCP8.5 and RCP8.5_FixA suggest that heavy precipitation associated with natural disasters will be aggravated in the future with aerosol mitigations.

Aerosol reductions increase R10 significantly over EA (Fig. 6d) but relatively insignificantly over SA (Fig. 7d) with time. Clearly, during 2031-2050, there is a decrease 

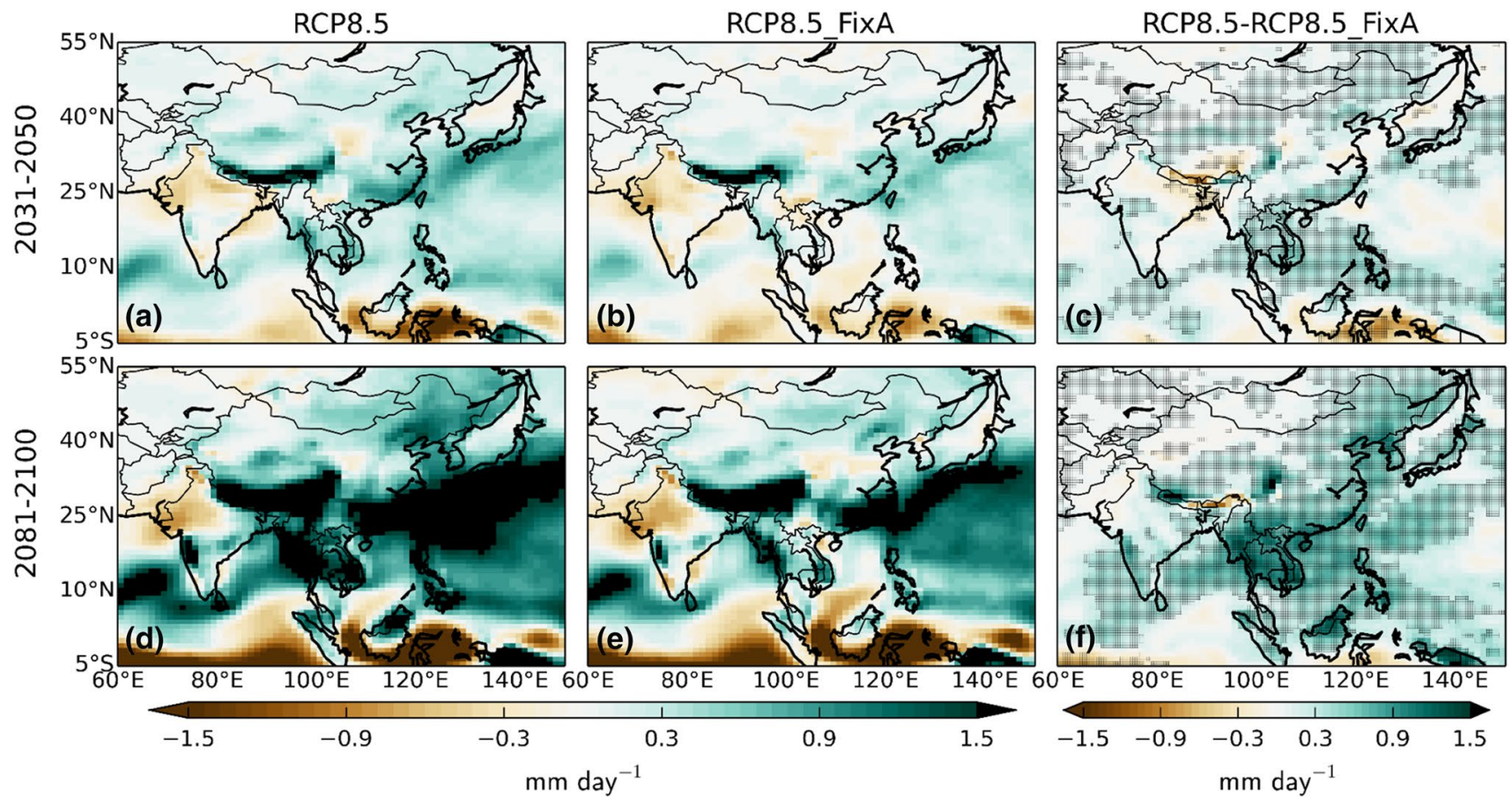

Fig. 8 Mean JJA precipitation (relative to 1986-2005 mean) $\left(\mathrm{mm} \mathrm{day}^{-1}\right)$ under a, $\mathbf{d}$ RCP8.5, b, e RCP8.5_FixA and $\mathbf{c}, \mathbf{f}$ their difference (RCP8.5 minus RCP8.5_FixA), averaged over 2031-2050

in R10 over SA and the Tibetan Plateau but an increase over EA (Fig. 9c), while aerosols increase over SA but decrease over EA (Fig. 5a-d). This suggests that aerosol increases can reduce the frequency of moderate-to-heavy $\left(\geq 10 \mathrm{~mm} \mathrm{day}^{-1}\right)$ precipitation events. What is noteworthy is that $\mathrm{SA}$ is projected to undergo relatively small aerosol increases coinciding with insignificant R10 decreases whereas EA sees a significant R10 increase associated with substantial aerosol mitigation. This suggests that R10 is sensitive to aerosol changes. Moreover, by comparing Figs. 8 and 9, it is clear that the aerosol induced changes in the spatial pattern of mean precipitation are very similar to that of R10. GHG increases result in CWD not changing much over EA (Fig. 6e) but decreasing over SA (Fig. 7e). Changing aerosols, by comparison, lead CWD to increase over EA but have little influence on CWD over SA. In addition, spatial differences in CWD (Fig. 9e, f) in general show opposite changes to AOD (Fig. 5g, h), suggesting the sensitivity of CWD to aerosols. Furthermore, the total amount of extreme precipitation (R95P) increases significantly over both SA and EA with GHG induced warming, while aerosol reductions increase R95P significantly on top of GHG effects. Changes in precipitation extremes are primarily driven by shifts in mean precipitation (Fig. S3a, c), which lead the frequency of R10 and R95P to increase, and hence result in significant changes in these precipitation extreme indices. In contrast, changes in precipitation (top) and 2081-2100 (bottom). The hatches in c, f denote the $95 \%$ statistical significance of the ensemble differences

variability have minor contributions (Fig. S3b, d) over both regions.

Figure 10 displays PDFs of mean and extreme precipitation indices over SA and EA for the baseline time period (1986-2005), as well as their future projections under the two scenarios. The PDFs are calculated using all ensemble members to ensure robustness. Note that the further to the right the PDF distribution is shifted, the more extreme the precipitation indices. Also see Fig. S4 in the supplementary file for the net contribution from aerosol reductions. There are similarities between the shift of the PDFs of mean and extreme precipitation, with again an exception of CWD over SA. Because of GHG increases under RCP8.5_FixA, the PDFs are flattened, and the mean value is increased. With aerosol reductions included, the shift of the PDFs is further reinforced: the moderate events and the lower part of the distribution are weakened while the higher values are further enhanced (also see Fig. S4). When compared to SA, the aerosol effects are more evident in EA-this is probably related to the larger aerosol reductions over EA by 2081-2100.

As shown in Figs. 6 and 7, the temporal evolution of summertime mean precipitation and extremes is related to the magnitude of warming. Therefore, we here investigate the percentage changes, relative to the 1986-2005 baseline, in spatially averaged precipitation indices in response to warming over SA and EA. The gradients of the changes against warming are obtained by regressing percentage changes in 

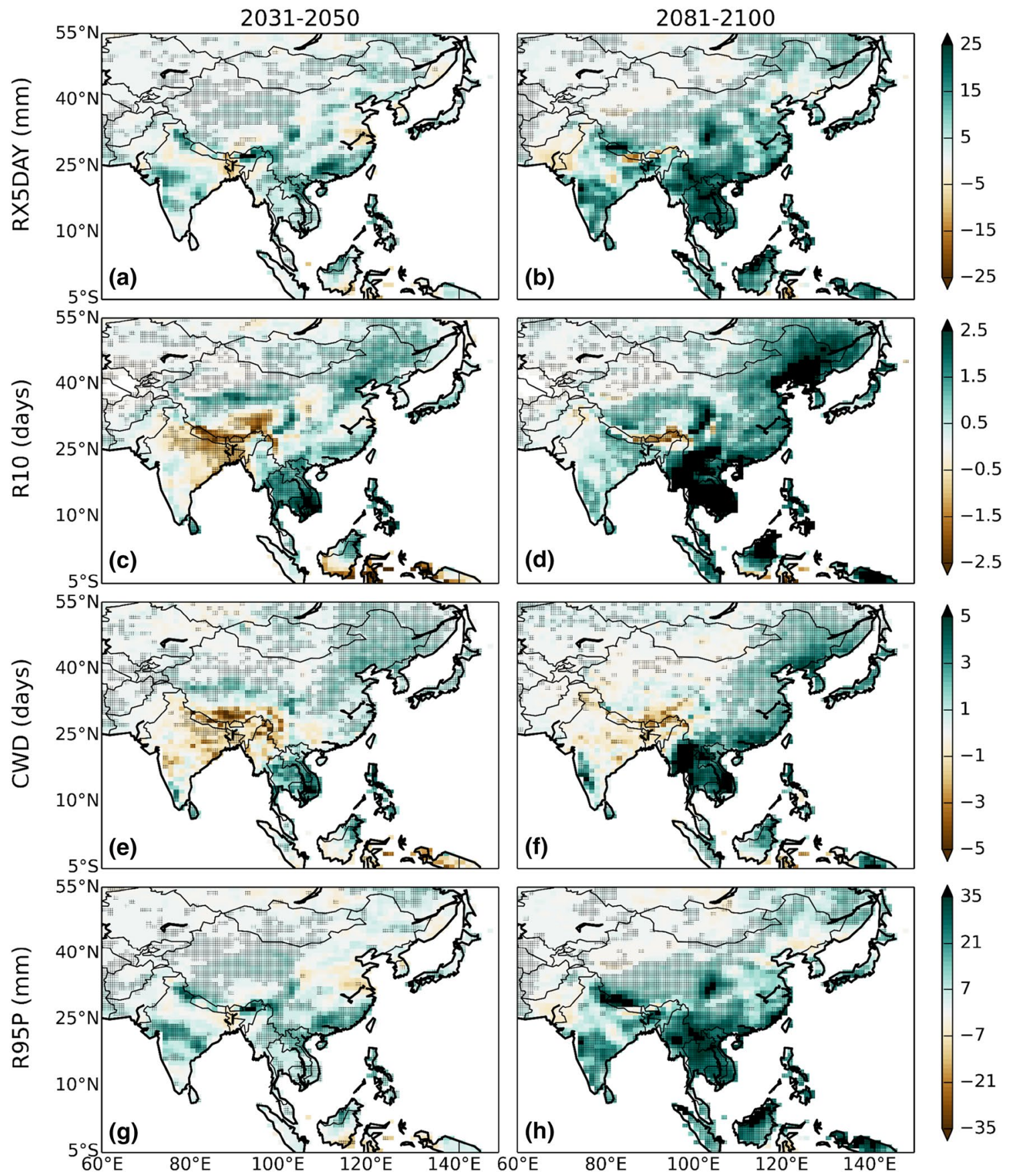

Fig. 9 Same as Fig. 8c, f, but for extreme precipitation indices: a, b RX5DAY (mm), c, d R10 (days), e, f CWD (days) and g, h R95P (mm) respectively, averaged over 2031-2050 (left) and 2081-2100 (right). The hatches denote 95\% statistical significance of ensemble differences

precipitation indices to the net warming following Lin et al. (2016), using 95 pairs (2006-2100) of data. For each year, the ensemble mean net temperature and precipitation indices changes are firstly computed, and net changes as a result of aerosol changes are isolated by contrasting the two ensemble means. The net changes in precipitation indices are then converted into percentage changes with respect to the baselines (1986-2005) before regression. Note however that here the net warming refers to local temperature increase rather than global as adopted by previous studies (Lin et al. 2016; Wang et al. 2016). The scatterplots and least square fits are shown in Fig. 11, and the gradients together with ensemble uncertainties are summarized in Table 2 . All the precipitation indices show a linear increase with warming from both GHG and aerosol forcing, with an exception of CWD over SA. In detail, the gradient of the percentage change of mean 


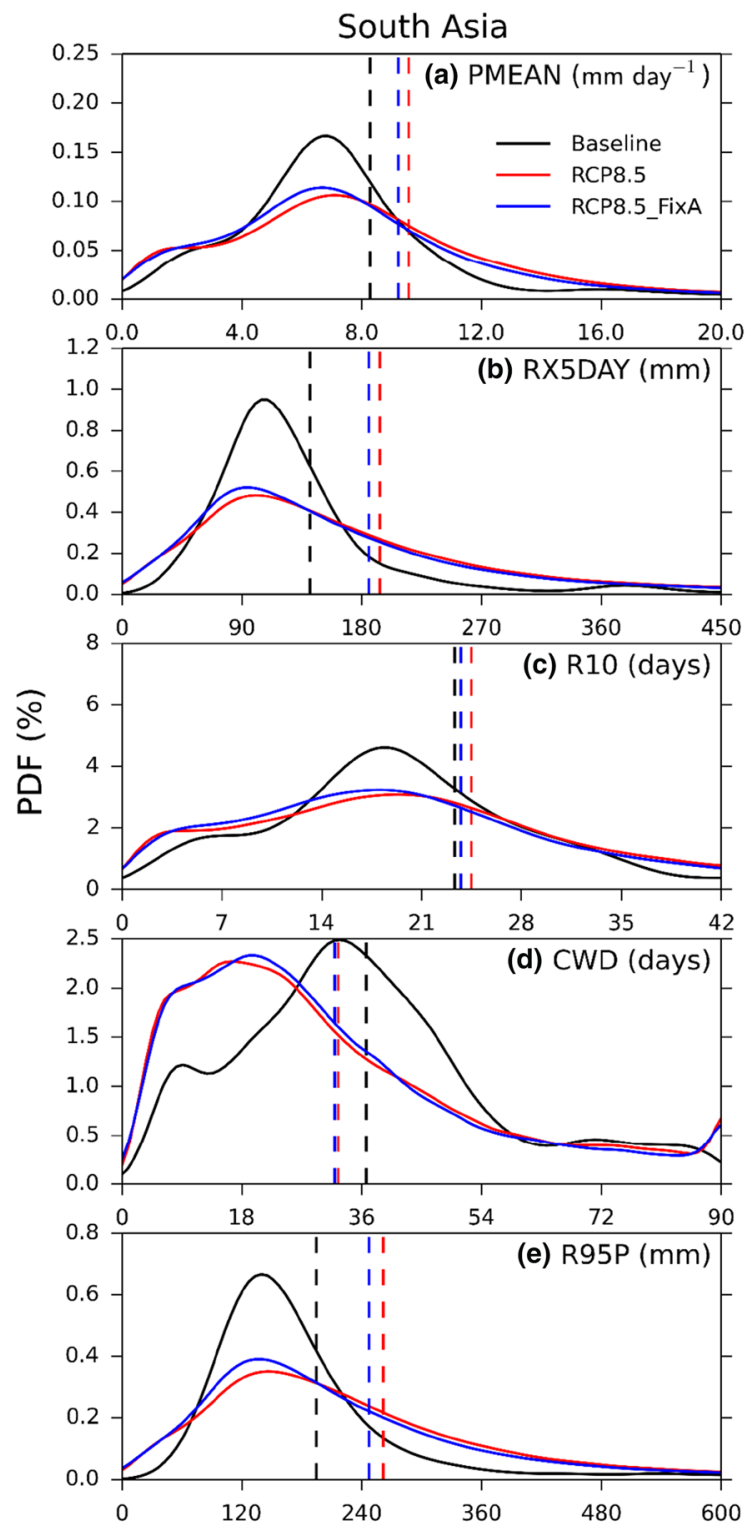

Fig. 10 Probability density functions (PDFs) of precipitation indices over South Asia $(\mathbf{a}-\mathbf{e})$ and East Asia $(\mathbf{f}-\mathbf{j})$. Black for the baseline (1986-2005), red for 2081-2100 under RCP8.5, and blue for 20812100 under RCP8.5_FixA. The vertical dashed lines are correspond-

precipitation does not differ much between SA and EA: $4.1 \%$ $\mathrm{K}^{-1}(\mathrm{SA})$ and $4.2 \% \mathrm{~K}^{-1}$ (EA) under RCP8.5, and $2.9 \% \mathrm{~K}^{-1}$ (SA) and $2.8 \% \mathrm{~K}^{-1}$ (EA) due to GHGs. However, a stronger response of aerosol reductions alone over EA (8.8\%) is found to be double that over SA $(4.2 \%)$. Table 2 shows that aerosols play a stronger role than GHGs in modulating precipitation extremes over EA relative to SA. For instance, with $1 \mathrm{~K}$ of aerosol reduction induced warming, there is an $11 \%$ increase in RX5DAY over EA, double that due to $1 \mathrm{~K}$ of GHG-induced warming (5.3\%). Similarly, over SA, RX5DAY increases by $11 \% \mathrm{~K}^{-1}$ for aerosol-induced warming, but only $7.5 \% \mathrm{~K}^{-1}$ for GHG-induced warming.

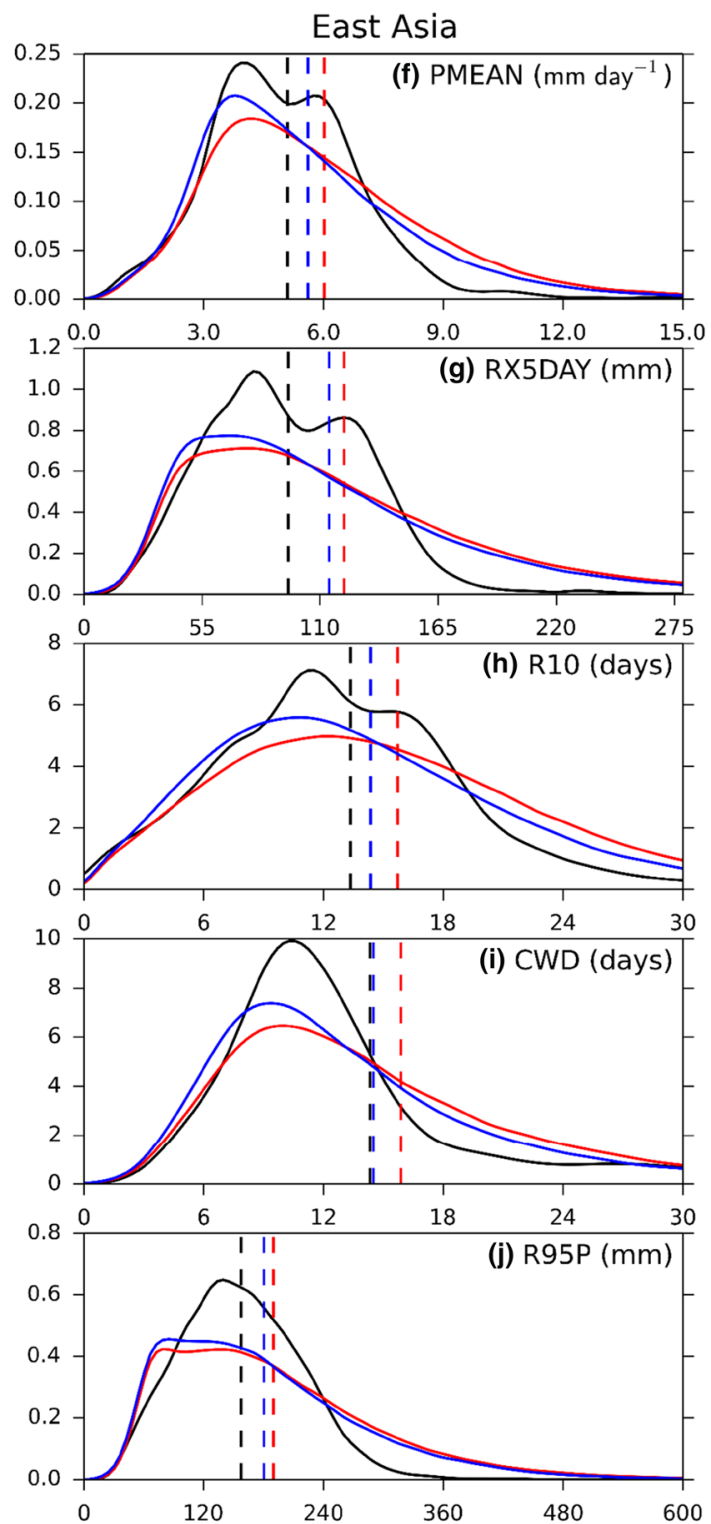

ing means of the PDF distributions. The PDFs are computed using 20 years of all grid-point data from all ensemble members over each region

\subsection{Responses of the Asian summer monsoon system}

The following section analyses and discusses the overall response of the Asian summer monsoon system, i.e., beyond precipitation, to aerosol changes, focusing on the two selected time periods (2031-2050 and 2081-2100).

Differences in cloud properties: low-level (surface to $850 \mathrm{hPa}$ ) cloud fraction (Fig. 12a, b), vertically integrated cloud droplet number concentration (CDNC, Fig. 12c, d), total grid-box cloud liquid water path (CLWP, Fig. 12e, f) and vertically averaged low-level cloud droplet effective 
Fig. 11 Percentage changes of a, f PMEAN, b, g RX5DAY, c, h R10, d, i CWD, and e, j R95P versus local surface warming over SA (left) and EA (right). Red for greenhouse gases (GHGs) plus anthropogenic aerosols under RCP8.5, blue for GHGs and black for anthropogenic aerosols only. Solid lines represent the gradients of changes derived through the least square fitting with p-value over 0.99
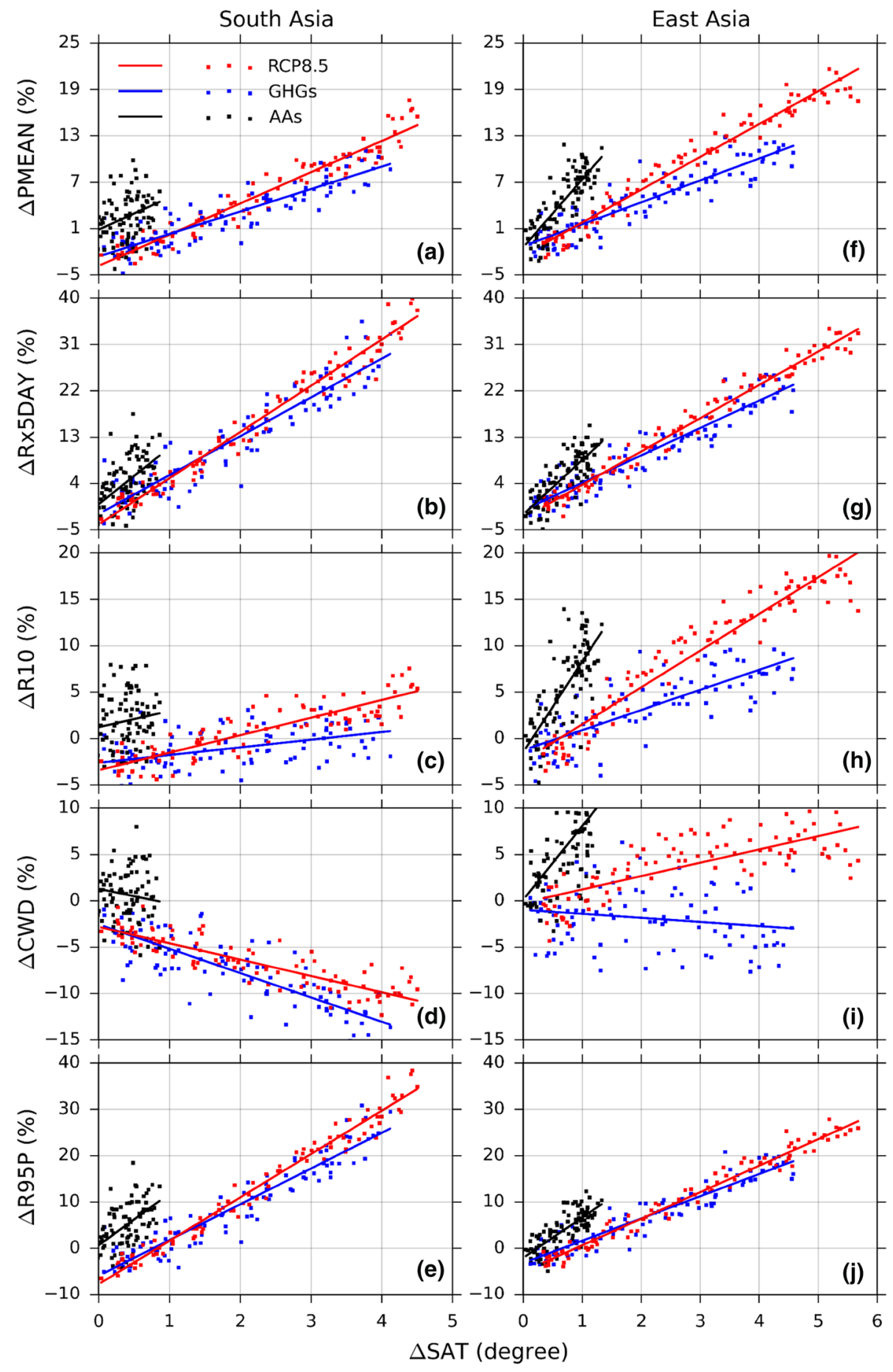

radius (CDER, Fig. 12g, h), are firstly examined. Although some differences at sub-regional scales aredue to the multitude of small-scale processes at play, all the above variables show consistent patterns of changes at the large scale. There is a larger magnitude decrease in cloud cover over a wider region by 2081-2100 (Fig. 12b) compared to 2031-2050 (Fig. 12a), due to larger aerosol reductions. Cloud changes are accompanied by a significant decrease in CDNC
(Fig. 12d, up to $-60 \%$ over large parts of EA) and CLWP (Fig. 12f, up to $-30 \%$ ). The above changes are suggestive of an overall important role of aerosol-cloud interactions in modulating the climate response over Asia: variations in aerosol emissions result in concurrent changes in CDNC, with the ensuing cloud-lifetime effect further leading to consistent variations in CLWP. Note however that CDNC is also dependent on environmental conditions, especially 
Table 2 Least square fitted gradients of percentage changes of precipitation indices against local warming

\begin{tabular}{|c|c|c|c|c|c|c|}
\hline & \multicolumn{3}{|c|}{ South Asia $\left(\% \mathrm{~K}^{-1}\right)$} & \multicolumn{3}{|c|}{ East Asia $\left(\% \mathrm{~K}^{-1}\right)$} \\
\hline & RCP8.5 & GHGs & AAs & RCP8.5 & GHGs & AAs \\
\hline PMEAN & $4.14(0.33)$ & $2.90(0.45)$ & $4.18(3.18)$ & $4.24(0.27)$ & $2.84(0.39)$ & $8.80(2.01)$ \\
\hline RX5DAY & $8.98(0.54)$ & $7.54(0.90)$ & $10.98(4.89)$ & $6.47(0.33)$ & $5.32(0.57)$ & $10.56(2.55)$ \\
\hline R10 & $1.89(0.33)$ & $0.83(0.51)$ & $1.74(3.45)$ & $3.96(0.33)$ & $2.16(0.51)$ & $9.72(2.61)$ \\
\hline CWD & $-1.77(0.33)$ & $-2.63(0.54)$ & $-1.58(3.33)$ & $1.44(0.39)$ & $-0.44(0.72)$ & $7.95(3.21)$ \\
\hline R95P & $9.36(0.51)$ & $7.71(0.81)$ & $11.13(4.74)$ & $5.72(0.30)$ & $4.80(0.51)$ & $8.69(2.28)$ \\
\hline
\end{tabular}

All results are significant at $99 \%$ levels from the $t$ test. Numbers inside brackets denote ensemble uncertainties the updraft velocity. More specifically, cloud condensation nuclei decreases lead to CDNC decreases because of reductions in cloud-active aerosols. With fewer cloud condensation nuclei, the conversion from cloud droplets into raindrops speeds up. These raindrops are precipitated efficiently, leading CLWP to drop substantially. Consequently, less cloud droplets are held in the clouds. The vertically average low level CDER (Fig. 12g, h), as might be expected, sees therefore broadly opposite trends to CDNC and CLWP, although some local inconsistencies exist.

Variations in aerosol loading and cloud properties can be related to changes in radiation. Figure 13 displays changes in clear-sky shortwave flux at the surface (FSNSC, Fig. 13a, b), all-sky shortwave flux at the surface (FSNS, Fig. 13c, d), and surface evaporation (Fig. 13g, h). Changes in FSNSC show general opposite trends to AOD (Fig. 5g, h). This is indicative of surface dimming from the aerosol direct effect. Aerosol-cloud interactions, together with water vapour changes (Fig. 12e, f), contribute to the difference between FSNS and FSNSC. For example, by 2081-2100, there is a widespread significant positive difference between FSNS (Fig. 13d) and FSNSC (Fig. 13b) over EA where a substantial aerosol reduction occurs under RCP8.5. That is, aerosol-cloud forcing, i.e. aerosol reduction induced decreases in low-level cloud fraction (Fig. 12a, b) and CLWP (Fig. 12e, f) and hence cloud albedo (not shown), results in more shortwave radiation reaching the surface. Furthermore, aerosol reduction leads to a significant increase in surface evaporation (Fig. 13e, f). This to some extent shows spatial agreement with precipitation changes (Fig. 8c, f). In fact, careful comparisons between changes in evaporation and changes in mean precipitation indicate that evaporation changes appear to explain the precipitation changes over northern EA. However, it was noted that the largest precipitation changes occur over Southeast Asia but the radiative forcing changes a.re over the northern part. This implies that precipitation changes over southern SA are driven by other factors such as changes in dynamics.

Given the dominant role of atmospheric dynamics in the seasonal evolution of the Asian monsoon, an analysis of atmospheric circulation changes provides important insights into the fundamental mechanism governing the monsoon system. Figure 14 shows that aerosol forcing has a significant impact on the large scale monsoon circulation. By 2031-2050, a net warming of around $0.7 \mathrm{~K}$ associated with aerosol reductions can be found over EA. In contrast, owing to continued aerosol increases over SA, the magnitude of warming over the Indian continent and the Northern Indian Ocean is relatively smaller, around $0.3 \mathrm{~K}$ (Fig. 14a). The SLP anomaly (Fig. 14c) features a strong anticyclone centred over NW India, developing as adjustment to increased regional aerosols and the muted warming compared to the neighbouring areas. This results in anomalous low-level north-easterlies over the Bay of Bengal and easterlies across S India, which obstruct the climatological south-westerlies from the Arabian Sea, and lead to anomalous moisture divergence (Fig. 14e) over Eastern India and the Bay of Bengal. Over EA, the large reduction in aerosols leads to a pronounced land warming compared to the ocean to the south and east, strengthening the land-sea thermal contrast, and to a collocated SLP reduction, reinforcing the climatological SLP gradient. As a result, the low-level south-westerlies are enhanced, and are accompanied by anomalous surface moisture convergence over a large part of EA and the South China Sea. In summary, by 2031-2050, aerosol reductions over EA and increases over SA result in a stronger East Asian summer monsoon circulation but a weaker South Asian summer monsoon circulation.

Atmospheric circulation changes are even more pronounced by 2081-2100, due to greater aerosol reductions over both SA and EA, thereby reversing and further continuing the trend during the first half of the twenty-first century, respectively. A distinct anomalous warming core, exceeding $1.5^{\circ} \mathrm{C}$, is located between north-eastern EA and Japan, resulting in a large reduction in SLP and an anomalous lower-tropospheric cyclonic circulation and associated anomalous northerlies over the EA land. This, as shown in Fig. 14f, impedes the north-eastward march of the moisture flux from the South China Sea to the land, leading to anomalous moisture divergence over the North China Plain but anomalous moisture convergence over South China and Southeast Asia. SA, on the contrary, 

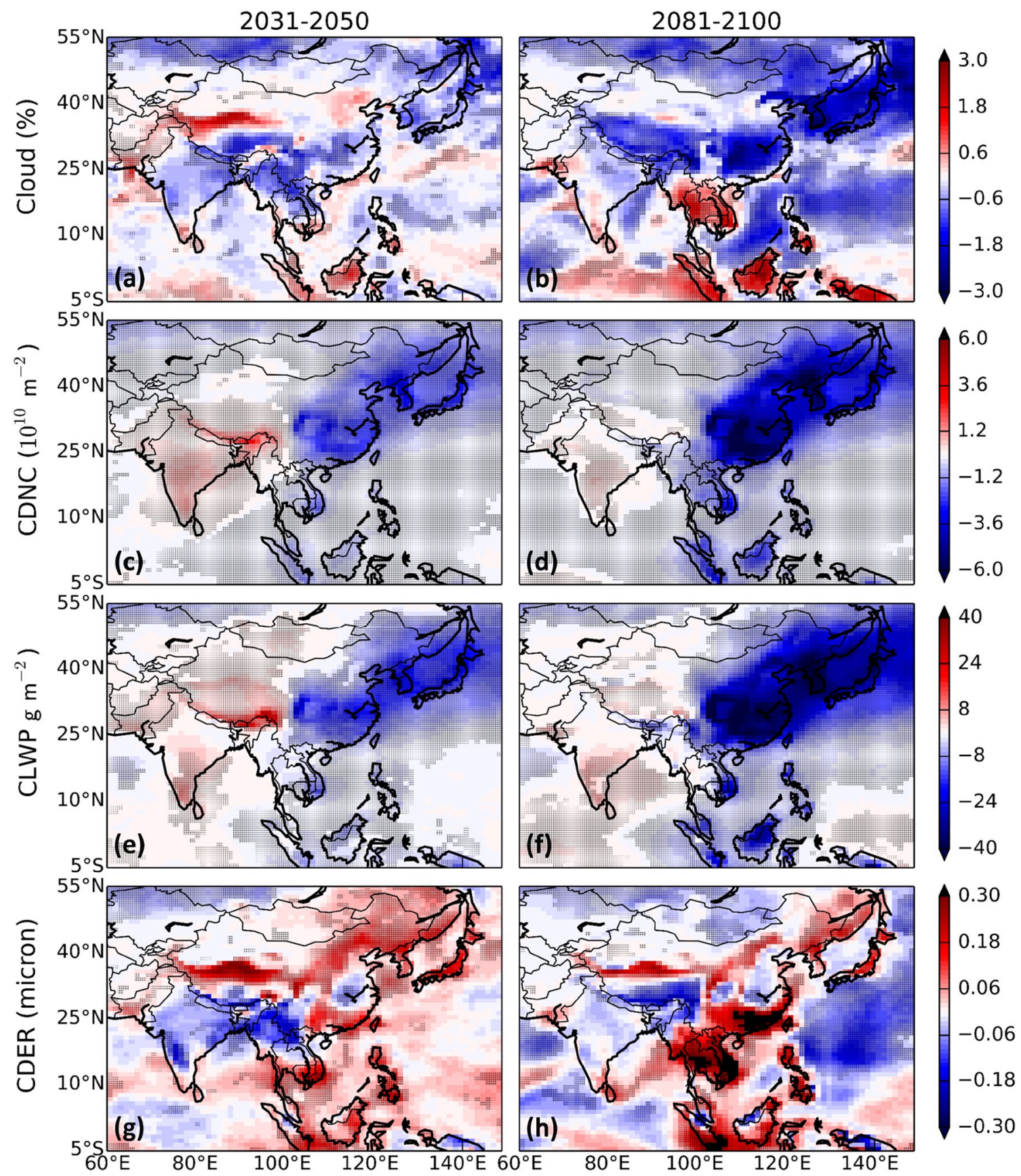

Fig. 12 Changes in JJA cloud properties associated with changes in anthropogenic aerosols. Respectively, a, b low-level (below the model $850 \mathrm{hPa}$ level) cloud fraction (Cloud, \%), c, d vertically integrated cloud droplet number concentration (CDNC, $10^{10} \mathrm{~m}^{-2}$ ), e, f

total grid-box cloud liquid water pathway (CLWP, $\mathrm{g} \mathrm{m}^{-2}$ ), and $\mathbf{g}, \mathbf{h}$ vertically averaged low-level effective cloud droplet radius (CDER, micron), averaged over 2031-2050 (left) and 2081-2100 (right). The hatches denote $95 \%$ statistical significance of ensemble differences

sees reinforced monsoonal circulation most evident over the Northern Indian Ocean and the Bay of Bengal, along with larger SLP increases over the ocean than the land (Fig. 14d). Moisture convergence anomalies over Southern India can also be seen. In summary, by the end of the century, with further aerosol reductions, the South Asian summer monsoon circulation is strengthened while the East Asian monsoon circulation is weakened.

The above analysis indicates an interplay between aerosol effects on clouds and radiation and atmospheric dynamics in determining the mean seasonal precipitation change over Asia. Specifically, over northern EA despite 


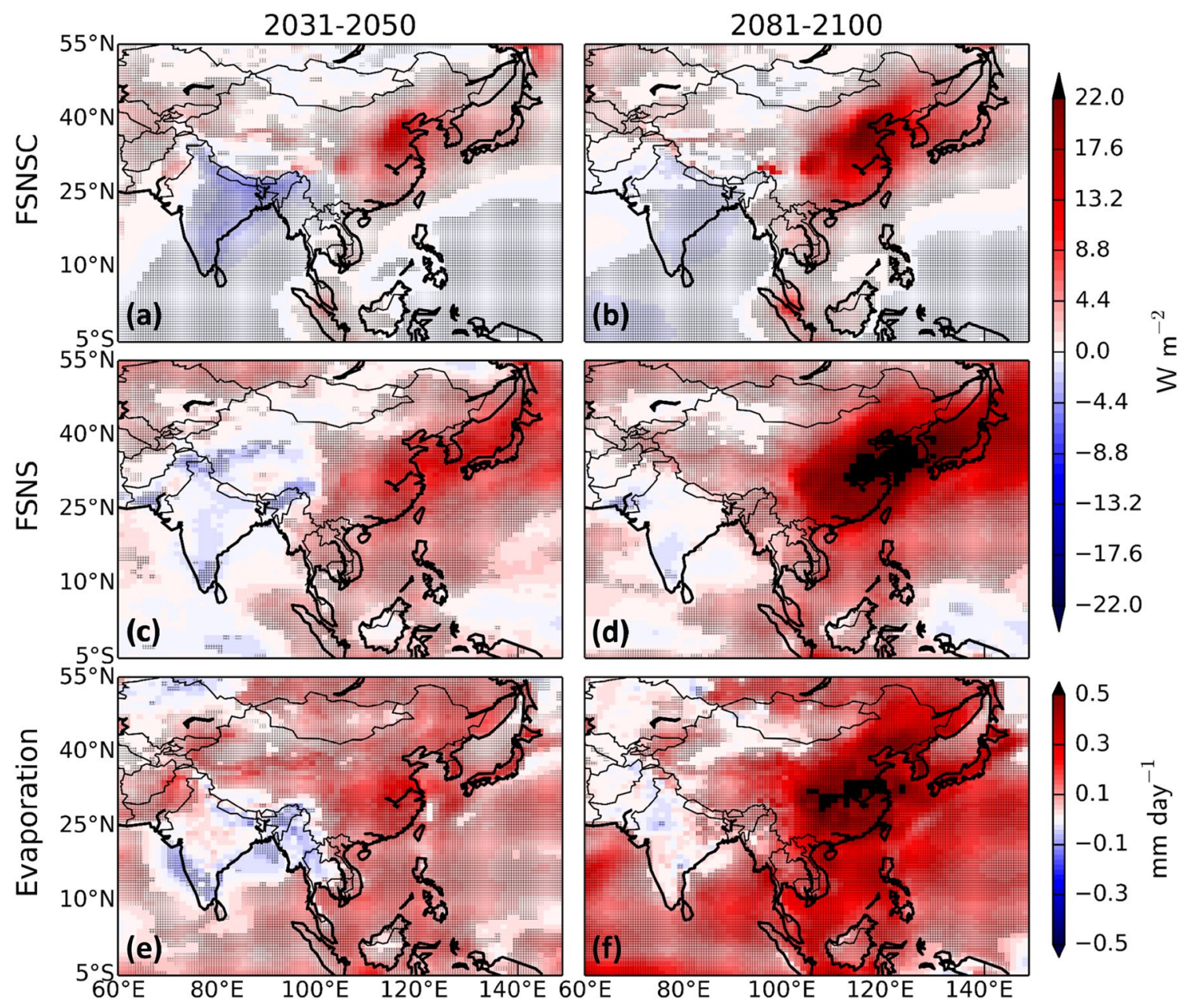

Fig. 13 Changes in JJA radiative and evaporative fluxes associated with changes in anthropogenic aerosols. Respectively, a, b clear-sky surface shortwave radiation (FSNSC, $\mathrm{W} \mathrm{m}^{-2}$ ), $\mathbf{c}, \mathbf{d}$ all-sky shortwave

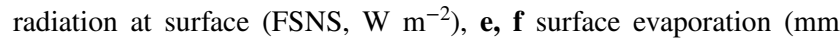
day $^{-1}$ ). The hatches denote $95 \%$ statistical significance of ensemble differences

a weaker atmospheric circulation and moisture divergence anomaly, precipitation increases due to the impacts of aerosol-radiation-cloud interactions on precipitation processes by 2081-2100. Conversely, over SA and southern EA, changes in precipitation by the end of the twenty-first century appear to be more directly linked to aerosol-induced changes in the large-scale circulation. This is supported by the enhanced moisture convergence anomalies which coincide well with changes in mean precipitation (compare Fig. $8 \mathrm{f}$ with 13f), and insignificant changes in cloud features and radiation.

\section{Discussion and concluding remarks}

Detecting the influence of aerosols on present-day precipitation extremes has proven to be a challenging task so far, critically limiting our confidence in identifying the drivers

of past variations in extremes and our ability to robustly project and understand future changes ( $\mathrm{Li}$ et al. 2017b). Internal variability of the climate system associated with atmospheric circulation has been recognised as a major hindering factor, as variability makes it hard to detect a signal amongst the 'noise'. Further, the Asian monsoon region is particularly sensitive to variations in precipitation, including extremes, due to the critical importance of precipitation for the agriculture and socioeconomic well-being of billions of people living there. Additionally, despite stringent emission controls in the near future, aerosol is likely to continue to play a major role in the coming decades over this region given the high present-day levels. This study addressed some knowledge gaps by making use of a large ensemble of coupled climate experiments for the twenty-first century under two different anthropogenic aerosol emissions scenarios. We investigated the roles of anthropogenic aerosols in future summertime precipitation extremes over the Asian 

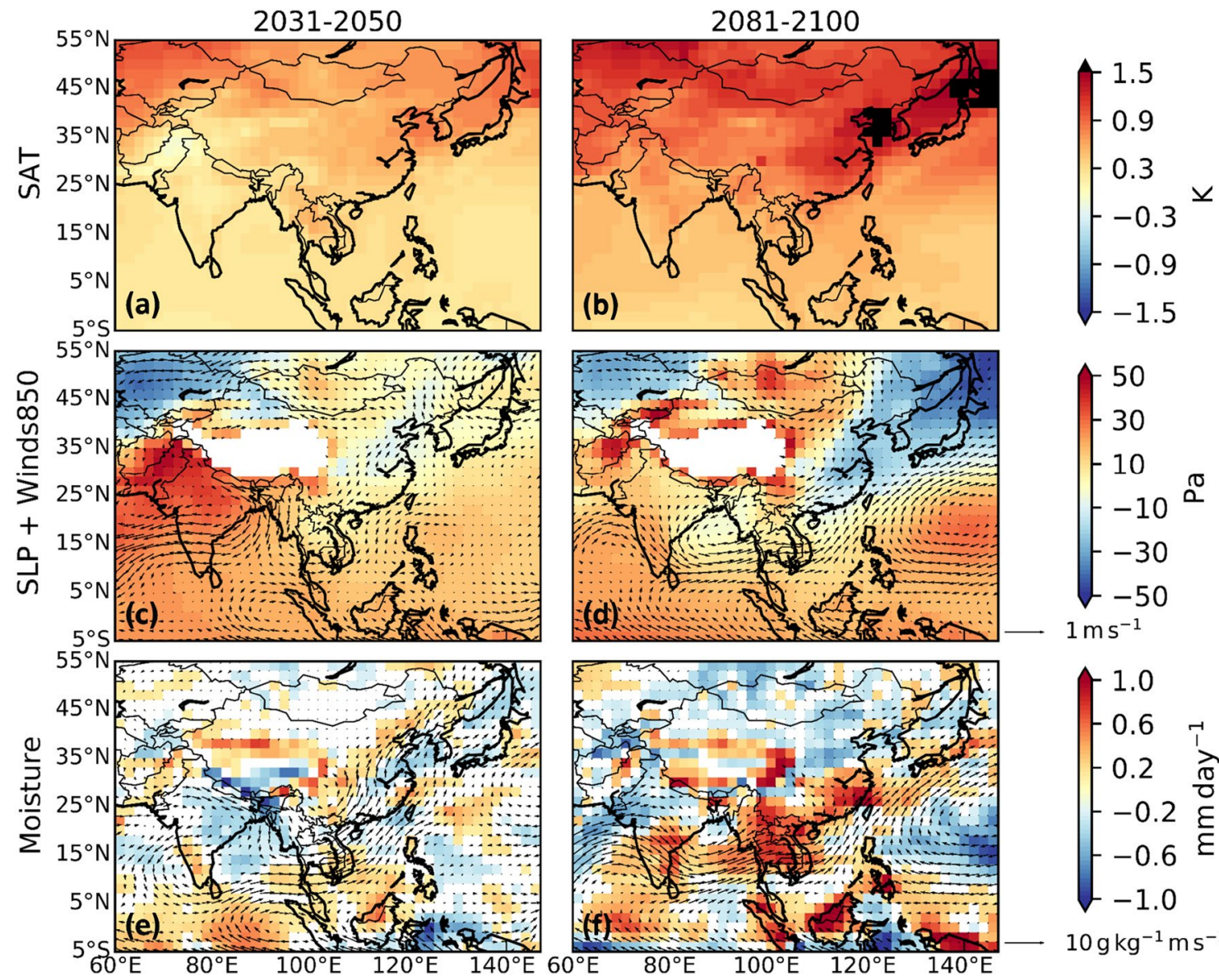

$1 \mathrm{~ms}^{-1}$

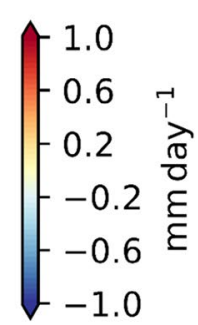

Fig. 14 Changes in JJA thermodynamic and dynamic fields associated with changes in anthropogenic aerosols. Respectively, a, b Surface air temperature (K), c, $\mathbf{d}$ sea level pressure (SLP, Pa, shadings) overlapped with Winds 850 ( $\mathrm{m} \mathrm{s}^{-1}$, arrows), and e, $\mathbf{f}$ vertically integrated moisture convergence $\left(\mathrm{mm}\right.$ day $^{-1}$, shadings, positive for con-

vergence, and only statistically significance changes ( $p$ value $\leq 0.05$ from the two-tailed student $\mathrm{t}$ test) are shown with color while insignificant changes are white) overlapped with $850 \mathrm{hPa}$ moisture flux $\left(\mathrm{g} \mathrm{kg}^{-1} \mathrm{~m} \mathrm{~s}^{-1}\right.$, arrows). Note that SLP and circulation fields over the Tibetan Plateau are masked off

monsoon region, by comparing ensemble simulations under the RCP8.5 scenario to those also under RCP8.5 but with fixed global aerosol emissions at 2005 levels. Note throughout the article we attribute such differences between RCP8.5 and RCP8.5_FixA to anthropogenic aerosol changes. Of course, the results can also be interpreted as the emergence of an underlying GHG signal as aerosols reduce, given the context that aerosols mask GHG effects in the present-day climate. The responses of cloud properties, radiative forcing, as well as thermodynamics and dynamics fields to aerosol changes were also investigated to elucidate the possible governing mechanisms. Our key findings are:

- Under the future RCP8.5 pathway following aerosol emission controls, we would expect a warmer and wetter climate over the Asian monsoon region, compared to the fixed 2005 aerosol scenario. Consequently, the drying trend of the Asian monsoon during the historical period will be alleviated. Also, the recently observed "Southern-
Flood-Northern-Drought" pattern over Eastern China will tend to reduce.

- Aerosol mitigation will lead to more severe precipitation extremes, including an increased likelihood of heavy precipitation related disasters during summertime over both SA and EA, more heavy precipitation days; more extreme precipitation and lengthier periods of consecutive wet days. There is a shift in the PDFs of precipitation extremes toward higher values over land by $2081-2100$, over EA in particular.

- Aerosols induce much stronger responses in extreme precipitation indices compared to GHGs, for the same amount of local surface warming: almost double the effect, as also pointed out by related works (Samset et al. 2018; Lin et al. 2016). We speculate that this is due to the higher aerosol efficiency than GHG in modulating solar radiation, surface energy fluxes, and cloud microphysics and dynamics, and hence induce stronger hydrological responses. Furthermore, the ratios between aerosol and 
GHG induced percentage changes of precipitation indices against local warming are larger over EA than SA.

- Aerosols generate a large response not only over the emission regions, but also far away. A representative example is over southern EA where precipitation increases, while aerosol reductions are more limited to the northern EA.

- The aerosol-induced imprint on precipitation changes appear to be mediated by different mechanisms over EA and SA, while aerosol-radiation-cloud interactions are the major contributor to the response over EA, atmospheric circulation changes dominate the response over SA.

Our results show that aerosol mitigation measures would increase precipitation in the future. This agrees with previous studies which concluded that the increasing anthropogenic aerosol forcing during the historical period, which was the dominant driver of the summer drying trend seen over the AMR, will be alleviated in the future with stringent aerosol emission legislations ( $\mathrm{Li}$ et al. 2015). In general, the South Asian summer monsoon circulation sees a weakening trend when aerosol emissions from SA increase during 2031-2050, but a strengthening trend when aerosol emissions reduce during 2081-2100. However, the East Asian summer monsoon circulation is projected to be reinforced during 2031-2050 with aerosol reductions, but weakened during 2081-2100 with additional aerosol reductions. The weakening of the East Asian summer monsoon circulation by 2081-2100 is driven by local thermodynamic and dynamic adjustments: the southward expansion of the Mongolia High towards northern China continent accompanying by an anomalous low over East and Northeast China and the adjacent oceans. This forces the Western Pacific Subtropical High (WPSH) to shift to south of the Yangtze River, and leads to the weakening of the East Asian summer monsoon circulation in northern and eastern land of China. This mechanism was also documented by previous studies [e.g. (Huang et al. 2007; Zhou et al. 2009)].

We acknowledge some limitations of this study. First of all, the experiments used in this analysis do not allow us to investigate the impact of changes to individual aerosol species, as they are all varying simultaneously. Yet, changes in different aerosol species show slightly different trajectories in the future especially over the SA. Additionally, aerosol effects are isolated, by comparing RCP8.5 and RCP8.5_FixA, under the assumption that aerosol effects can be linearly added to other forcing agents. However, the non-linear interactions between GHGs and aerosols should be carefully noted. Also, despite the dominant role of local aerosols in determining the local responses, there can also be contributions from remote aerosols. E.g., localised AOD changes may give rise to localised radiative forcing, but these changes to the energy budget affect climate much more widely (Shindell and Faluvegi 2009). Bollasina et al. (2014) found that local aerosols dominate precipitation changes over India while remote aerosols contribute as well over the late twentieth century. Guo et al. $(2015,2016)$ indicated that remote aerosols contribute to changes in the large-scale background precipitation. In addition, this study is based upon only one model which has limitations in many aspects. For instance, the representation of aerosol effects, and especially the indirect effects. A caveat that needs to be clarified is that the cloud droplet lifetime effect in CAM5 has been recently questioned from observational evidence (Malavelle et al. 2017). This was further investigated by Zhou and Penner (2017) who found that the increase of the liquid water path in CAM5 is caused by a large decrease of the autoconversion rate when cloud droplet number increases. As such, our results should be interpreted in the context of the structural limitation of CESM1, although the large ensemble experiments do provide a solid framework to provide information on internal variability.

To summarize, the CESM model indicates that major changes in anthropogenic aerosols over the coming century are likely to have significant impacts on precipitation extremes over Asia, and will likely further enhance the rainfall changes brought about by continued GHG increases. These projections have large uncertainties, related to poorly constrained model representations of certain processes, with different mechanisms operating in different regions. Given the consequences of these projected changes for society, constraining these uncertainties will be crucially important. Therefore, careful studies on the interactions between future Asian aerosol emissions trajectories and regional to largescale climate dynamics are critical for effective climate risk management in this highly populated and vulnerable region.

Acknowledgements Alcide Zhao acknowledges the China Scholarships Council/University of Edinburgh Joint Scholarship. The authors thank the two anonymous reviewers for their insightful and valuable comments. We acknowledge the Asian Precipitation-Highly-Resolved Observational Data Integration towards Evaluation of Water Resources for the availability of the daily precipitation dataset, and the National Centres for Environmental Prediction/National Centre for Atmospheric Research for providing the surface temperature and winds data. We acknowledge the Community Earth System Model project at the National Centre for Atmosphere Research (NCAR) and the supercomputing resources provided at the National Science Foundation and the Office of Science of the US department of Energy.

Open Access This article is distributed under the terms of the Creative Commons Attribution 4.0 International License (http://creativeco mmons.org/licenses/by/4.0/), which permits unrestricted use, distribution, and reproduction in any medium, provided you give appropriate credit to the original author(s) and the source, provide a link to the Creative Commons license, and indicate if changes were made. 


\section{References}

Alexander L et al (2006) Global observed changes in daily climate extremes of temperature and precipitation. J Geophys Res Atmos 111:D05109. https://doi.org/10.1029/2005JD006290

Ali H, Mishra V (2017) Contrasting response of rainfall extremes to increase in surface air and dewpoint temperatures at urban locations in India. Sci Rep 7:1228

Ali H, Mishra V (2018) Contributions of dynamic and thermodynamic scaling in subdaily precipitation extremes in India. Geophys Res Lett 45:2352-2361

Allen MR, Ingram WJ (2002) Constraints on future changes in climate and the hydrologic cycle. Nature 419:224-232

Ashfaq M, Rastogi D, Mei R, Touma D, Leung LR (2017) Sources of errors in the simulation of south Asian summer monsoon in the CMIP5 GCMs. Clim Dyn 49:193-223

Bartlett R, Bollasina M, Booth B, Dunstone N, Marenco F (2016) Impacts of East Asian aerosols on the Asian monsoon. In: EGU general assembly conference abstracts, $\mathrm{p} 16671$

Bollasina MA, Ming Y, Ramaswamy V (2011) Anthropogenic aerosols and the weakening of the South Asian summer monsoon. Science 334:502-505

Bollasina MA, Ming Y, Ramaswamy V, Schwarzkopf MD, Naik V (2014) Contribution of local and remote anthropogenic aerosols to the twentieth century weakening of the South Asian Monsoon. Geophys Res Lett 41:680-687

Boucher O et al (2013) Clouds and aerosols. In: Climate change 2013: the physical science basis. Contribution of working group I to the fifth assessment report of the intergovernmental panel on climate change. Cambridge University Press, Cambridge, UK. New York, NY, USA, pp 571-657

Brücker G (2005) Vulnerable populations: lessons learnt from the summer 2003 heat waves in Europe. Eurosurveillance 10:147

Burke C, Stott P (2017) Impact of anthropogenic climate change on the East Asian summer monsoon. J Clim 30:5205-5220

Caesar J, Lowe JA (2012) Comparing the impacts of mitigation versus non-intervention scenarios on future temperature and precipitation extremes in the HadGEM2 climate model. J Geophys Res Atmos 117:D15109. https://doi.org/10.1029/2012JD017762

Chu P-S, Chen YR, Schroeder TA (2010) Changes in precipitation extremes in the Hawaiian Islands in a warming climate. J Clim 23:4881-4900

Chung CE, Ramanathan V (2006) Weakening of North Indian SST gradients and the monsoon rainfall in India and the Sahel. J Clim 19:2036-2045

Conley AJ et al (2012) Description of the NCAR community atmosphere model (CAM 5.0) NCAR technical note NCAR/TN464+STR. https://doi.org/10.5065/D63N21CH

Crippa $\mathrm{M}$ et al (2016) Forty years of improvements in European air quality: regional policy-industry interactions with global impacts. Atmos Chem Phys 16:3825-3841

Deng J, Xu H (2016) Nonlinear effect on the East Asian summer monsoon due to two coexisting anthropogenic forcing factors in eastern China: an AGCM study. Clim Dyn 46:3767-3784

Deser C, Phillips A, Bourdette V, Teng H (2012) Uncertainty in climate change projections: the role of internal variability. Clim Dyn 38:527-546

Dong B, Sutton RT, Highwood EJ, Wilcox LJ (2016) Preferred response of the East Asian summer monsoon to local and non-local anthropogenic sulphur dioxide emissions. Clim Dyn 46:1733-1751

Easterling DR, Meehl GA, Parmesan C, Changnon SA, Karl TR, Mearns LO (2000) Climate extremes: observations, modeling, and impacts. Science 289:2068-2074
Easterling DR, Kunkel KE, Wehner MF, Sun L (2016) Detection and attribution of climate extremes in the observed record. Weather Clim Extremes 11:17-27

Fan J, Wang Y, Rosenfeld D, Liu X (2016) Review of aerosol-cloud interactions: mechanisms, significance, and challenges. J Atmos Sci 73:4221-4252

Flato G et al (2013) Evaluation of climate models. In: Climate change 2013: the physical science basis. Contribution of working group I to the fifth assessment report of the intergovernmental panel on climate change climate change 2013, vol 5, pp 741-866

Freychet N, Hsu H-H, Chou C, Wu C-H (2015) Asian summer monsoon in CMIP5 projections: a link between the change in extreme precipitation and monsoon dynamics. J Clim 28:1477-1493

Freychet N et al (2016) Variability of hydrological extreme events in East Asia and their dynamical control: a comparison between observations and two high-resolution global climate models. Clim Dyn 48:745-766

Frich P, Alexander L, Della-Marta P, Gleason B, Haylock M, Tank AK, Peterson T (2002) Observed coherent changes in climatic extremes during the second half of the twentieth century. Clim Res 19:193-212

Gillett NP, Von Salzen K (2013) The role of reduced aerosol precursor emissions in driving near-term warming. Environ Res Lett 8:034008

Giorgi F, Francisco R (2000) Uncertainties in regional climate change prediction: a regional analysis of ensemble simulations with the HADCM2 coupled. AOGCM Clim Dyn 16:169-182

Giorgi F, Im E-S, Coppola E, Diffenbaugh N, Gao X, Mariotti L, Shi Y (2011) Higher hydroclimatic intensity with global warming. J Clim 24:5309-5324

Gong DY, Ho CH (2002) Shift in the summer rainfall over the Yangtze River valley in the late 1970s. Geophys Res Lett. https:// doi.org/10.1029/2001GL014523

Guo L, Turner AG, Highwood EJ (2015) Impacts of 20th century aerosol emissions on the South Asian monsoon in the CMIP5 models. Atmos Chem Phys 15:6367-6378

Guo L, Turner AG, Highwood EJ (2016) Local and remote impacts of aerosol species on Indian summer monsoon rainfall in a GCM. J Clim 29:6937-6955

Hagos SM, Leung LR, Yoon JH, Lu J, Gao Y (2016) A projection of changes in landfalling atmospheric river frequency and extreme precipitation over western North America from the large ensemble CESM simulations. Geophys Res Lett 43:1357-1363. https://doi.org/10.1002/2015GL067392

Hansen J, Sato M, Glascoe J, Ruedy R (1998) A common-sense climate index: is climate changing noticeably? Proc Natl Acad Sci 95:4113-4120

Haywood J, Ramaswamy V (1998) Global sensitivity studies of the direct radiative forcing due to anthropogenic sulfate and black carbon aerosols. J Geophys Res Atmos 103:6043-6058

Held IM, Soden BJ (2006) Robust responses of the hydrological cycle to global warming. J Clim 19:5686-5699

Huang R, Chen J, Huang G (2007) Characteristics and variations of the East Asian monsoon system and its impacts on climate disasters in China. Adv Atmos Sci 24:993-1023

Hurrell JW et al (2013) The community earth system model: a framework for collaborative research. Bull Am Meteorol Soc 94:1339-1360

Hwang YT, Frierson DM, Kang SM (2013) Anthropogenic sulfate aerosol and the southward shift of tropical precipitation in the late 20th century. Geophys Res Lett 40:2845-2850

Jiang Y, Liu X, Yang X-Q, Wang M (2013) A numerical study of the effect of different aerosol types on East Asian summer clouds and precipitation. Atmos Environ 70:51-63

Kalnay E et al (1996) The NCEP/NCAR 40-year reanalysis project. Bull Am Meteorol Soc 77:437-471 
Kay J et al (2015) The Community Earth System Model (CESM) large ensemble project: a community resource for studying climate change in the presence of internal climate variability. Bull Am Meteorol Soc 96:1333-1349

Kharin VV, Zwiers F, Zhang X, Wehner M (2013) Changes in temperature and precipitation extremes in the CMIP5 ensemble. Clim Change 119:345-357

Knapp AK et al (2008) Consequences of more extreme precipitation regimes for terrestrial ecosystems. Bioscience 58:811-821

Koch D, Del Genio A (2010) Black carbon semi-direct effects on cloud cover: review and synthesis. Atmos Chem Phys 10:7685-7696

Lamarque J-F et al (2011) Global and regional evolution of shortlived radiatively-active gases and aerosols in the representative concentration pathways. Clim Change 109:191-212

Lau WK-M, Kim K-M (2017) Competing influences of greenhouse warming and aerosols on Asian summer monsoon circulation and rainfall Asia-Pacific. J Atmos Sci 53:181-194

Li X, Ting M, Li C, Henderson N (2015) Mechanisms of Asian summer monsoon changes in response to anthropogenic forcing in CMIP5 models. J Clim 28:4107-4125

Li $\mathrm{S}$ et al (2016a) Impact of aerosols on regional climate in southern and northern China during strong/weak East Asian summer monsoon years. J Geophys Res Atmos 121:4069-4081

Li Z et al (2016b) Aerosol and monsoon climate interactions over Asia. Rev Geophys 54:866-929. https://doi.org/10.1002/2015R G000500

Li C et al (2017a) India is overtaking China as the world's largest emitter of anthropogenic sulfur dioxide. Sci Rep 7:14304

Li H, Chen H, Wang H (2017b) Effects of anthropogenic activity emerging as intensified extreme precipitation over China. $\mathbf{J}$ Geophys Res Atmos 122:2

Lin L, Gettelman A, Fu Q, Xu Y (2015) Simulated differences in 21st century aridity due to different scenarios of greenhouse gases and aerosols. Clim Change 146:407-422

Lin L, Wang Z, Xu Y, Fu Q (2016) Sensitivity of precipitation extremes to radiative forcing of greenhouse gases and aerosols. Geophys Res Lett 43:9860-9868

Liu X et al (2012) Toward a minimal representation of aerosols in climate models: description and evaluation in the community atmosphere model CAM5. Geosci Model Dev 5:709

Lohmann U, Lüönd F, Mahrt F (2016) An introduction to clouds: from the microscale to climate. Cambridge University Press, Cambridge

Lu Z, Zhang Q, Streets DG (2011) Sulfur dioxide and primary carbonaceous aerosol emissions in China and India, 1996-2010. Atmos Chem Phys 11:9839-9864

Ma S et al (2017) Detectable anthropogenic shift toward heavy precipitation over eastern China. J Clim 30:1381-1396

Malavelle FF et al (2017) Strong constraints on aerosol-cloud interactions from volcanic eruptions. Nature 546:485

Mascioli NR, Fiore AM, Previdi M, Correa G (2016) Temperature and precipitation extremes in the United States: quantifying the responses to anthropogenic aerosols and greenhouse gases. $\mathbf{J}$ Clim 29:2689-2701

Mateos D, Antón M, Sanchez-Lorenzo A, Calbó J, Wild M (2013) Long-term changes in the radiative effects of aerosols and clouds in a mid-latitude region (1985-2010). Glob Planet Change 111:288-295

Min S-K, Zhang X, Zwiers FW, Hegerl GC (2011) Human contribution to more-intense precipitation extremes. Nature 470:378-381

Mukherjee S, Aadhar S, Stone D, Mishra V (2018) Increase in extreme precipitation events under anthropogenic warming in India. Weather Clim Extremes 20:45-53

O'Gorman PA (2015) Precipitation extremes under climate change. Curr Clim Change Rep 1:49-59
Orlowsky B, Seneviratne SI (2012) Global changes in extreme events: regional and seasonal dimension. Clim Change 110:669-696

Paul S, Ghosh S, Oglesby R, Pathak A, Chandrasekharan A, Ramsankaran R (2016) Weakening of Indian summer monsoon rainfall due to changes in land use land cover. Sci Rep 6:32177

Pendergrass AG, Hartmann DL (2014) The atmospheric energy constraint on global-mean precipitation change. J Clim 27:757-768

Peterson TC et al (2013) Monitoring and understanding changes in heat waves, cold waves, floods, and droughts in the United States: state of knowledge. Bull Am Meteorol Soc 94:821-834

Polson D, Hegerl G, Allan R, Sarojini BB (2013) Have greenhouse gases intensified the contrast between wet and dry regions? Geophys Res Lett 40:4783-4787

Polson D, Bollasina M, Hegerl G, Wilcox L (2014) Decreased monsoon precipitation in the Northern Hemisphere due to anthropogenic aerosols. Geophys Res Lett 41:6023-6029

Qian C, Zhou T (2014) Multidecadal variability of North China aridity and its relationship to PDO during 1900-2010. J Clim 27:1210-1222

Ramanathan V et al (2005) Atmospheric brown clouds: impacts on South Asian climate and hydrological cycle. Proc Natl Acad Sci USA 102:5326-5333

Ramanathan V et al (2007) Atmospheric brown clouds: hemispherical and regional variations in long-range transport, absorption, and radiative forcing. J Geophys Res Atmos 112:D22S21. https://doi. org/10.1029/2006JD008124

Riahi K, Grübler A, Nakicenovic N (2007) Scenarios of long-term socio-economic and environmental development under climate stabilization. Technol Forecast Soc Change 74:887-935

Samset BH, Sand M, Smith CJ, Bauer SE, Forster PM, Fuglestvedt JS, Osprey S, Schleussner C-F (2018) Climate impacts from a removal of anthropogenic aerosol emissions. Geophys Res Lett 45:1020-1029

Sanap S, Pandithurai G, Manoj M (2015) On the response of Indian summer monsoon to aerosol forcing in CMIP5 model simulations. Clim Dyn 45:2949-2961

Sen Roy S, Balling RC (2004) Trends in extreme daily precipitation indices in India. Int J Climatol 24:457-466

Shindell D, Faluvegi G (2009) Climate response to regional radiative forcing during the twentieth century. Nat Geosci 2:294

Shindell DT, Faluvegi G, Rotstayn L, Milly G (2015) Spatial patterns of radiative forcing and surface temperature response. J Geophys Res Atmos 120:5385-5403

Sillmann J, Pozzoli L, Vignati E, Kloster S, Feichter J (2013a) Aerosol effect on climate extremes in Europe under different future scenarios. Geophys Res Lett 40:2290-2295

Sillmann J, Kharin V, Zwiers F, Zhang X, Bronaugh D (2013b) Climate extremes indices in the CMIP5 multimodel ensemble: Part 2. Future climate projections. J Geophys Res Atmos 118:2473-2493

Sillmann J, Kharin V, Zhang X, Zwiers F, Bronaugh D (2013c) Climate extremes indices in the CMIP5 multimodel ensemble: Part 1. Model evaluation in the present climate. J Geophys Res Atmos 118:1716-1733

Singh D, Tsiang M, Rajaratnam B, Diffenbaugh NS (2013) Precipitation extremes over the continental United States in a transient, high-resolution, ensemble climate model experiment. J Geophys Res Atmos 118:7063-7086

Singh D, Tsiang M, Rajaratnam B, Diffenbaugh NS (2014) Observed changes in extreme wet and dry spells during the South Asian summer monsoon season. Nat Clim Change 4:456-461

Song F, Zhou T, Qian Y (2014) Responses of East Asian summer monsoon to natural and anthropogenic forcings in the 17 latest CMIP5 models. Geophys Res Lett 41:596-603

Stocker T (2014) Climate change 2013: the physical science basis: working group I contribution to the fifth assessment report of the 
Intergovernmental panel on climate change. Cambridge University Press, Cambridge, New York, USA

Tebaldi C, Hayhoe K, Arblaster JM, Meehl GA (2006) Going to the extremes. Clim Change 79:185-211

Van Rij E (2016) An approach to the disaster profile of People's Republic of China 1980-2013. Emerg Disaster Rep 3:1-48

Van Vuuren DP et al (2011) The representative concentration pathways: an overview. Clim Change 109:5

Wang B (2006) The Asian monsoon. Springer/Praxis Publishing Co, New York, $\mathrm{p} 787$

Wang Z, Lin L, Yang M, Xu Y (2016) The effect of future reduction in aerosol emissions on climate extremes in China. Clim Dyn 47:2885-2899

Wang L, Wu Z, He H, Wang F, Du H, Zong S (2017) Changes in summer extreme precipitation in Northeast Asia and their relationships with the East Asian summer monsoon during 1961-2009. Int J Climatol 37:25-35

Wentz FJ, Ricciardulli L, Hilburn K, Mears C (2007) How much more rain will global warming bring? Science 317:233-235

Westervelt D, Horowitz L, Naik V, Golaz J-C, Mauzerall D (2015) Radiative forcing and climate response to projected 21 st century aerosol decreases. Atmos Chem Phys 15:12681-12703

Westra S, Alexander LV, Zwiers FW (2013) Global increasing trends in annual maximum daily precipitation. J Clim 26:3904-3918

Xie S-P, Lu B, Xiang B (2013) Similar spatial patterns of climate responses to aerosol and greenhouse gas changes. Nat Geosci 6:828-832
Xu Y, Lamarque J-F, Sanderson BM (2015) The importance of aerosol scenarios in projections of future heat extremes. Clim Change 146:393-406

Yatagai A, Kamiguchi K, Arakawa O, Hamada A, Yasutomi N, Kitoh A (2012) APHRODITE: constructing a long-term daily gridded precipitation dataset for Asia based on a dense network of rain gauges. Bull Am Meteorol Soc 93:1401-1415

Yihui D, Chan JC (2005) The East Asian summer monsoon: an overview. Meteorol Atmos Phys 89:117-142

Yu R, Li J, Yuan W, Chen H (2010) Changes in characteristics of latesummer precipitation over eastern China in the past 40 years revealed by hourly precipitation data. J Clim 23:3390-3396

Zhai P, Zhang X, Wan H, Pan X (2005) Trends in total precipitation and frequency of daily precipitation extremes over China. J Clim 18:1096-1108

Zhang X et al (2011) Indices for monitoring changes in extremes based on daily temperature and precipitation data Wiley interdisciplinary reviews. Clim Change 2:851-870

Zhou C, Penner JE (2017) Why do general circulation models overestimate the aerosol cloud lifetime effect? A case study comparing CAM5 and a CRM. Atmos Chem Phys 17:21-29

Zhou T, Gong D, Li J, Li B (2009) Detecting and understanding the multi-decadal variability of the East Asian Summer Monsoonrecent progress and state of affairs. Meteorol Z 18:455-467

Zhou B, Wen QH, Xu Y, Song L, Zhang X (2014) Projected changes in temperature and precipitation extremes in China by the CMIP5 multimodel ensembles. J Clim 27:6591-6611 